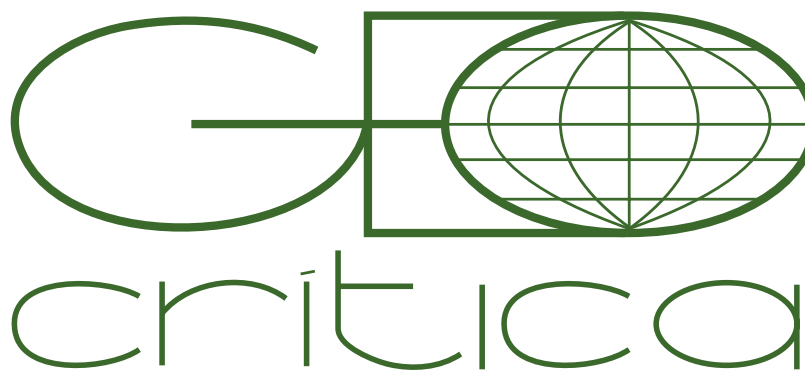

\section{Scripta Nova}

Revista Electrónica de Geografía y Ciencias Sociales Universitat de Barcelona

\title{
CIENCIA FORESTAL, PRÁCTICA TÉCNICA, POLÍTICA DE LA MADERA Y CONTEXTO COLONIAL EN GUINEA ECUATORIAL (1929-1968)
}

\author{
Juan Carlos Guerra Velasco \\ Departamento de Geografía. Universidad de Valladolid \\ guerra@geo.uva.es
}

Recibido: 24/4/18; Devuelto para correcciones: 2/7/18; Aceptado: 9/10/18

\section{Ciencia forestal, práctica técnica, política de la madera y contexto colonial en Guinea Ecuatorial (1929-1968) (Resumen)}

Desde mediados de la década de 1920, la explotación maderera de las selvas de la actual República de Guinea Ecuatorial conoce una intensa transformación: deja de estar protagonizada por determinadas compañías comerciales europeas para convertirse en una práctica colonial sustentada por la afluencia de importantes capitales financieros metropolitanos. Tomando como referencia inicial 1929, año en el que se crea el Servicio Forestal de los Territorios Españoles en el Golfo de Guinea, el trabajo expone una doble evolución: la de la administración forestal en la colonia y la de los conocimientos silvícolas que se trasladan o se producen dentro de ella. La primera muestra la forma que el Servicio acaba adquiriendo con el tiempo. La segunda permite vislumbrar cómo los cuatro conceptos nucleares de la silvicultura científica -medida, renovación, beneficio y regulación- adquieren un significado nuevo con la práctica que el colonialismo español despliega en el Golfo de Guinea.

Palabras clave: Guinea Ecuatorial, colonialismo, silvicultura, extractivismo forestal

\section{Forest science, technical practice, wood policy and colonial context in Equato- rial Guinea (1929-1968) (Abstract)}

From the mid 1920's, wood production in the forest of Equatorial Guinea undergoes an intense transformation. It ceases to being controlled by certain European commercial companies and turns into a colonial practice supported by the influx of important Spanish financial resources/funds. Taking as an initial point of reference 1921, when the Forestry Commission of the Spanish Territories in the Gulf of Guinea was created, the present study deals with a double development: the forest administration in the colony and the forest knowledge and how it is transferred or produced within the colony. The first one shows the actual role of the Commission. The second one allows to grasp how the four key concepts of scientific forestry (i.e. measure, renewal, profit and regulation) adopt a new nuance as per the practice that Spanish colonialism displays in the Gulf of Guinea

Key Words: Equatorial Guinea; colonialism; silviculture; forest extractivism 
Al desarrollo del imperialismo europeo de finales del siglo XIX y de la práctica colonial que lo acompaña contribuyen los saberes de carácter científico. Dentro de éstos desempeñan una función trascendente los conocimientos relacionados, en su sentido más amplio, con el espacio. Son un elemento fundamental en el diseño del proyecto imperial y en el ejercicio del poder colonial. ${ }^{1}$ En cuanto saber que tiene como materia prima un elemento con una evidente dimensión territorial, la ciencia forestal europea y los profesionales que la encarnan participan plenamente de la dominación y transformación del espacio que implica el colonialismo. El abastecimiento sostenido de maderas sirve para desplegar una racionalidad al servicio del mercado metropolitano que permite mostrar la hegemonía técnica de las potencias europeas, desarrollar nuevas formas de control territorial en las colonias y aspira a encauzar bajo una lógica capitalista la vitalidad de la selva. ${ }^{2}$

La silvicultura científica puede definirse en ese momento como la aplicación de métodos científicos de ecología forestal para conseguir la mayor producción de madera con fines comerciales. Es un cálculo instrumental en el que el valor del bosque está definido en términos de material "output". ${ }^{3}$ Esto hace que se identifique plenamente con los objetivos del capitalismo industrial que se desarrolla en Europa desde los comienzos del siglo XIX. El encaje entre ambos lo propician cuatro conceptos nucleares que rompen con los saberes silvícolas precedentes: medida, renovación, beneficio y regulación. ${ }^{4}$ El primero por la necesidad de saber con cuánta madera se dispone; el segundo con objeto de garantizar la pervivencia del bosque; el tercero como reflejo directo de la lógica que impone el capitalismo industrial y el último como expresión del control necesario para que la renovación y el beneficio sean posibles. Su manifestación en el espacio es la ordenación de montes; es decir, la instauración de mecanismos de aprovechamiento del arbolado que propicien una producción sostenida y regular de madera y la obtención de una renta estable y segura.

Estos principios se trasladan a la colonia; pero el contacto con ésta provoca que en su ejecución práctica se expresen de una forma diferente a la original. Desde un punto de vista técnico, el trabajo con ecosistemas forestales extraños al ámbito en el que nace la moderna silvicultura hace emerger un problema trascendente por sus implicaciones: cómo manejar bosques en los que un reducido número de especies de interés comercial y con una baja representación por unidad de superficie se desarrolla en un conjunto notablemente mayor que no las tiene. ${ }^{5} \mathrm{La}$ silvicultura europea levanta su cuerpo científico sobre la medida y la renovación de masas monoespecíficas, en donde todos o gran parte de los taxones que las componen poseen un aprovechamiento industrial. Con independencia de que se

1 Blais, Deprest y Singaravélou, 2011

2 Lanz, 2000; Cleary, 2005

3 Lanz, 2000

4 Dargavel y Johann, 2013

5 Aubrèville, 1929; Bergeret, 1993; Munshi, 1996; Dargavel y Johann, 2013 
confíe en el desarrollo de aplicaciones técnicas que permitan el aprovechamiento de la madera de más especies, la respuesta a la singularidad que posee la selva exige reelaborar los preceptos traídos desde Europa. Las vías que se ensayan son diversas, si bien comparten un denominador común una vez que se abandona por inabordable la sustitución de especies: incrementar la densidad de los pies de interés industrial mediante procedimientos no demasiado costosos. Se trata de "mejorar" la composición futura en especies aprovechables del bosque tropical, de "enriquecerlo" según el discurso forestal colonial.

La intervención forestal no se resuelve sólo en términos de ecología forestal. Para que el conocimiento científico pueda ser aplicado, es necesario dotarlo de instrumentos operativos y de determinadas construcciones espaciales. Es decir, la ciencia se transforma en política, y ésta pivota sobre un triple control: el territorial del bosque, el de la obtención de los productos más lucrativos de la selva y el de la mano de obra necesaria para las labores intensivas en fuerza de trabajo. ${ }^{6}$

Con estos principios se arman los servicios forestales coloniales que las metrópolis europeas ponen en marcha en África y Asia a lo largo de las últimas décadas del siglo XIX y primeras del XX.7 Todos asumen una doble función técnica y fiscal, y en su desarrollo es posible reconocer, según algunos autores, un progresivo y trascendente cambio de pensamiento. Si en un principio la conservación parece impregnar el modo de explotación colonial de la selva, la demanda creciente de madera que inaugura la Primera Guerra Mundial da paso a una mentalidad extractiva que se prolonga hasta el momento de la descolonización. ${ }^{8}$

El caso de la administración forestal colonial y de la práctica silvícola española en la Guinea continental es singular. En comparación con las colonias vecinas su desarrollo es tardío e incompleto. ${ }^{9}$ La silvicultura no tiene la propiedad de ser performativa. Contrariamente a lo defendido por algunos autores, la presencia de un ingeniero de montes no inaugura la ciencia de montes en la colonia ni garantiza el aprovechamiento sostenido de la selva. ${ }^{10}$ Hace falta una práctica. Ésta, por otro lado, forma parte desde hace ya tiempo en ese momento de los trabajos de los ingenieros de

6 Vandergest y Lee, 2006

7 Buchy, 1993; Bryant, 1996; Lanz, 2000; Vandergest y Lee, 2006; Weil, 2006; Dargevel y Johann, 2013; Garrido, 2014; McElwee, 2016; Tano, 2016; Guerra y Pascual, 2017

8 Weil, 2006

9 El Servicio de Montes del Protectorado español en el Norte de Marruecos es de 1913. Esta celeridad no se da en el caso de la Guinea continental. El Servicio Forestal de los Territorios Españoles en el Golfo de Guinea nace en 1929, unos años después de que las colonias vecinas hayan puesto en funcionamiento los suyos -Costa de Marfil en 1912, Gabón y el Congo Francés en 1922 y el Camerún como colonia francesa en 1924, si bien ya contaba con uno bajo el dominio alemán anterior a la Primera Guerra Mundial-. En el caso francés, aparecen no pocos de los problemas que después se manifiestan en la experiencia española: escaso interés por el trabajo técnico en las colonias e insuficiencia de recursos financieros. No obstante, los forestales franceses en las colonias de África ecuatorial desarrollan con el tiempo numerosos trabajos que, desde un punto de vista experimental, pretenden resolver los problemas silvícolas que conlleva la gestión maderera de la selva.

10 García Esteban y Martínez, 2000; García Pereda, 2013 y 2015 
montes españoles en la metrópoli. Durante la segunda mitad del siglo XIX elaboran un notable cuerpo doctrinal que les permite, a través de las ordenaciones de montes y los trabajos de repoblación, desplegar una intensa actividad técnica a lo largo de gran parte de la centuria posterior. ${ }^{11}$

Este trabajo se estructura en cuatro grandes bloques. En el primero se exponen las principales características de la economía forestal que se levanta en la Guinea continental durante el período colonial español; en el segundo y tercero se presenta a los principales productores de conocimiento silvícola de carácter técnico-científico, y en el cuarto y último se explica el giro que la silvicultura canónica experimenta en el contacto con la colonia. El grueso de la documentación utilizada proviene del Fondo África del Archivo General de la Administración (AGA).

\section{El nacimiento de una economía forestal y el desarrollo del régimen concesional en la Guinea continental}

Al poner fin a la "Cuestión del Muni", el Tratado de París de 1900 entre España y Francia convierte en incontrovertible la presencia española en el occidente del África Ecuatorial, si bien reducida en su parte continental a un cuadrilátero de $26.000 \mathrm{~km}^{2}$ de superficie entre los ríos Campo y Muni. No obstante, no es hasta bien entrada la década de 1920 cuando la ocupación colonial española, las estructuras administrativas que conlleva y las construcciones espaciales que crea rebasan la franja litoral en la que hasta ese momento se halla contenida para extenderse al interior del continente.

En dicho avance desempeña una función relevante el negocio forestal. Éste se transforma profundamente a mediados de los años veinte. Hasta entonces responde al capitalismo comercial que despliegan por las costas del Golfo de Guinea determinadas compañías europeas. A partir de ese momento se transforma en una práctica de carácter colonial: responde a una economía extractiva; implica el control físico de la selva y el administrativo de sus aprovechamientos; introduce una malla de límites que se impone a la espacialidad de las comunidades nativas; conlleva un fuerte control de la mano de obra y se enmarca en un proyecto más amplio de dominación social y cultural de la colonia. ${ }^{12}$ Las características de este negocio ya han sido expuestas: con profundidad para una primera etapa (1926-1936) y esbozadas en sus rasgos esenciales para el recorrido posterior que culmina con la descolonización en $1968 .{ }^{13}$ Sirvan como resumen algunas ideas. El negocio está protagonizado por capitales financieros españoles con sociedades que se comportan como compañías coloniales. Éstas convierten a la madera en el principal epígrafe de exportación de la colonia, tanto en volumen como en valor. ${ }^{14}$ El predominio inicial del ocume se matiza a partir de la primera mitad

11 Gómez, 1992; Gómez y Mata, 1992; Casals, 1996; Pemán, Iriarte y Lario, 2017.

12 Pascual y Guerra, 2017

13 Guerra y Pascual, 2015a y Guerra y Pascual, 2015b, 2017

14 Carnero y Díez, 2014 


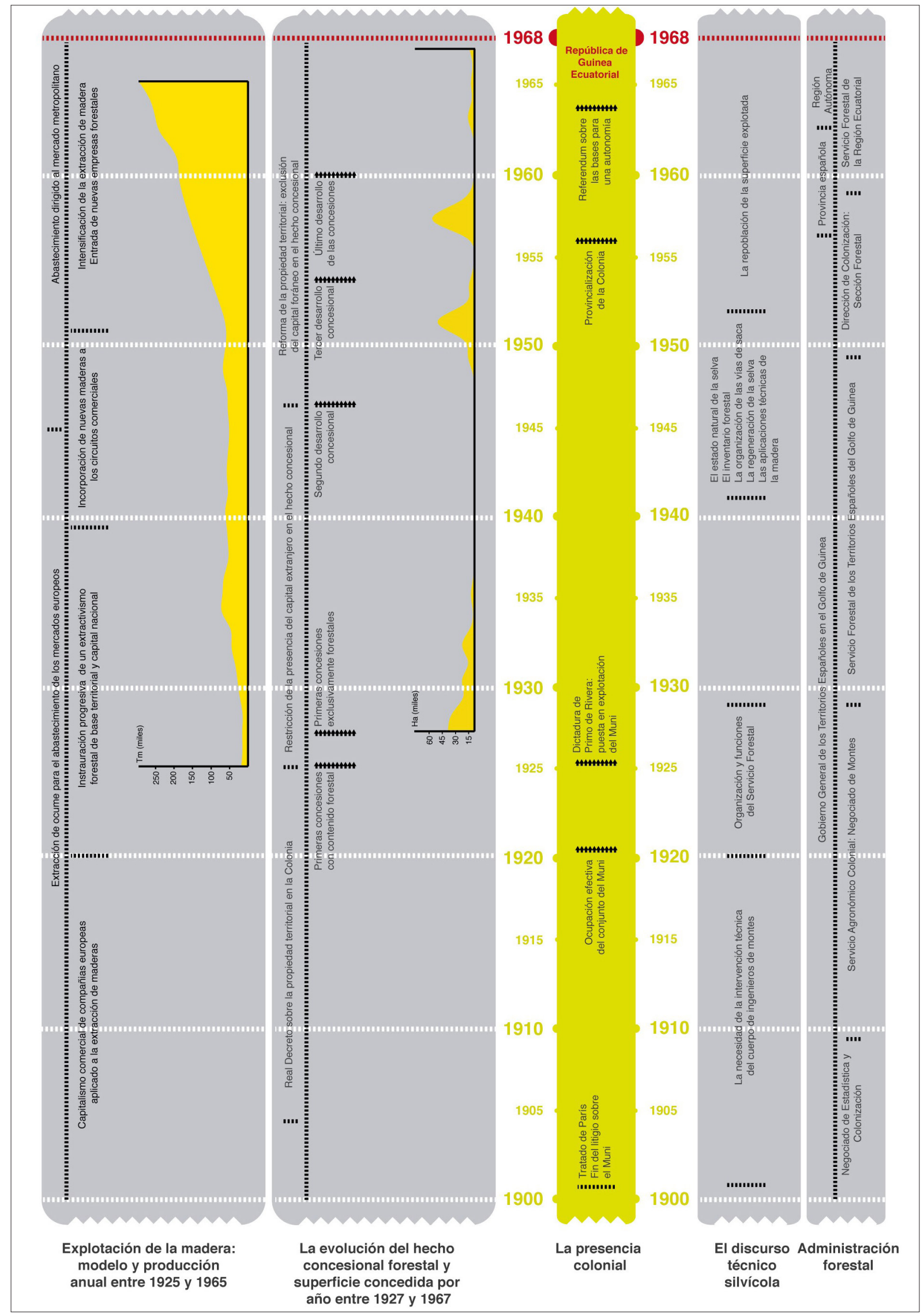

Figura 1. Los tiempos forestales de la Guinea continental en el período colonial Fuente: Elaboración a partir de diversas informaciones 
de la década de 1940: comienzan a ser aprovechadas nuevas especies para el desenrollo -hasta un total de diecisiete, entre las que sobresale el acom-y para el aserrío -alabó, asia, ukola o samanguilla-. En esos mismos años se vive otro cambio. El comercio pasa de dirigirse a los mercados europeos a través del puerto de Hamburgo para abastecer mayoritariamente al mercado metropolitano. ${ }^{15}$ Por último, las concesiones forestales actúan como intermediación física entre el Estado y las compañías coloniales. El volumen de ocume exportado es de unas 15.000 Tm en 1926 y alcanza las 360.000 en 1966. A su vez, en esta última fecha la suma de la superficie explotada en algún momento por las compañías concesionarias alcanza las $327.000 \mathrm{Ha}$, a las que hay que sumar la madera que proviene de los desbosques de las fincas agrícolas y la que se extrae de las reservas territoriales de los poblados nativos.

Con independencia de en qué mercado se coloque, no se puede entender la extracción de madera de la colonia sin acudir a un hecho determinante cuyo alcance rebasa ampliamente la realidad española: la evolución técnica en la transformación industrial de la madera. A lo largo de los siglos XIX y XX se reconocen en el mundo desarrollado unos usos de la madera declinantes, otros renovados y, por último, otros emergentes. ${ }^{16}$ Entre estos últimos se encuentra la elaboración de tableros contrachapados. Comienzan a fabricarse en Estonia a finales del XIX, extendiéndose rápidamente su producción por Europa. En un inicio se recurre al desenrollo de la madera de abedul, a la que se suma en una proporción cada vez mayor la del ocumen proveniente de las colonias francesas del África ecuatorial -esencialmente del Gabón- y de la Guinea española. España no queda al margen de ese negocio emergente. De hecho, aunque no forma parte de los argumentos de este trabajo, durante no poco tiempo se asiste en torno a un intenso debate entre coloniales y tableristas; es decir, entre las empresas forestales en la colonia y los fabricantes de tablero contrachapado en la metrópoli. Estos suman 17 instalaciones en 1935, para superar la centena poco más de veinte años después. ${ }^{17}$ Los trabajos fiscales a los que obliga el control de este negocio son los que justifican la creación del Servicio Forestal de los Territorios Españoles del Golfo de Guinea en 1929. Su vida posterior está condicionada por las características de la colonia y por el contexto en el que se desenvuelve la economía forestal de la metrópoli (Figura 1).

\section{La administración forestal en la colonia}

Desde 1901, la Revista de Montes reclama el aprovechamiento de las selvas de la Guinea continental y la intervención técnica del cuerpo de ingenieros de montes. ${ }^{18}$ A pesar

15 El mercado metropolitano absorbe en torno a un 30 \% de la madera extraída entre 1927 y 1939 , para incrementarse hasta el $95 \%$ entre 1940 y 1968

16 Zapata, 2001

17 Zapata, 2001

18 Revista de Montes, 1901, 583; 1913, 867 y 923; 1917, 963 
del reiterado anuncio de la inminente creación de un servicio forestal, ésta no se produce hasta 1929; y no lo hace como resultado de un plan premeditado sino como consecuencia de un conflicto corporativo en la administración colonial. Antes de esa fecha, los recursos humanos y materiales que el Estado pone al servicio de la explotación forestal son, a grandes rasgos, los mismos que actúan en la administración de Fernando Póo desde las últimas décadas del siglo XIX..$^{19} \mathrm{Al}$ ser resultado directo de los trabajos de desbosque para la agricultura de plantación fernandina, los asuntos forestales se encuadran primero en el Negociado de Estadística y Colonización y a partir de 1910-1911 en el Servicio Agronómico Colonial. Sólo desde el momento en el que el hecho concesional adquiere carta de naturaleza, un ayudante de montes destacado en Bata atiende de forma permanente el continente. La llegada de Miguel Núñez de Prado como Gobernador General a la colonia en 1926 con el encargo de intensificar la ocupación y explotación del Muni acelera los acontecimientos. A principios de 1927 se convoca un concurso para cubrir una plaza de ingeniero de montes que ocupa poco después por Manuel Carrera. ${ }^{20} \mathrm{Al}$ poco de llegar a la colonia realiza junto con el gobernador general una expedición al interior del continente. El resultado es la elaboración de un informe que, con el objeto de encauzar la política forestal, retrata la situación de la colonia y anticipa algunas de las iniciativas que se despliegan en los años posteriores. ${ }^{21}$ Propone la creación de un servicio forestal

"con independencia propia para verificar los estudios botánico-tecnológico precisos, así como para estudiar las vías de saca naturales y verificar reconocimientos al objeto de inventariar la riqueza forestal de la colonia; la realización con toda urgencia de una misión forestal entre Ingenieros de Montes, Industriales y Colonos que se dediquen a la explotación de maderas, al objeto de realizar reconocimientos y recoger muestras de madera para su posterior análisis y comparación con la que importamos del extranjero"

y la

“creación en España de una Sección dedicada única y exclusivamente al estudio-tecnológico de la maderas africanas" radicada en el "Instituto de Experiencias Técnico Forestales". 22

El Servicio Forestal se crea en 1929, pero no es el resultado del guion antes esbozado. Parece que desde el momento en el que se cubre la nueva plaza surgen tensiones entre el jefe del servicio, ingeniero agrónomo y residente en Santa Isabel,

19 Costa y Calle, 2007

20 Gaceta de Madrid del 4 de enero y del 11 de febrero de 1927

21 AGA 81/6464

22 AGA 81/6464. Esta sección, como tal, no llegó a crearse. En realidad, se refiere al Instituto Nacional de Experiencias Agronómicas y Forestales. En 1929 se transforma en el Instituto Forestal de Investigaciones y Experiencias. Su fusión con el Patronato de Biología Animal y con el Instituto Nacional de Investigaciones Agronómicas en 1971 dan lugar al Instituto Nacional de Investigaciones Agrarias (INIA) 
y el ingeniero de montes. Las alimenta, además de la subordinación del segundo al primero, el reparto de las tasas que proceden del deslinde de las fincas concedidas para la explotación de los bosques o para ser destinadas al cultivo agrícola. ${ }^{23} \mathrm{El}$ conflicto se resuelve en su parte económica con la asignación del trabajo de deslinde a los peritos y el establecimiento de un sistema de distribución de emolumentos más amplio. En la administrativa, la solución que se adopta es la segregación de la Oficina Forestal del Servicio Agronómico. Nace así el Servicio Forestal de los Territorios Españoles del Golfo de Guinea. Es difícil atribuir a este hecho un sentido político, científico o de práctica colonial que vaya más allá del puramente nominal, toda vez que un año después se discute cuál debe ser el alcance, contenido y medios humanos y materiales del nuevo órgano administrativo.

Si bien el informe de Carrera es anterior a la creación de la administración forestal en la colonia, de alguna forma anticipa un atributo que se mantiene hasta bien avanzada la década de 1950: su carácter inacabado, en permanente construcción o reconstrucción. En ese intervalo de tiempo son abundantes los memorandos, documentos e informaciones que señalan la necesidad de reformar el Servicio conforme a lo que se espera de él. ${ }^{24}$ Para responder a esto último es necesario tener en cuenta que lo que se pide a las selvas del Muni es madera. Y no una madera cualquiera, sino aquélla que puede poner remedio, en distintas circunstancias históricas, a alguno de los problemas de la economía forestal española. ${ }^{25} \mathrm{Si}$ los bosques de la Guinea continental se imaginan desde la metrópoli como un espacio de provisión, es coherente que se piense en una administración capaz de movilizar progresivamente sus recursos forestales, de dominar el conjunto del territorio continental y de afrontar todas las dimensiones técnicas de la silvicultura tropical y fiscales de la explotación colonial del bosque.

En la construcción de esa personalidad inacabada confluyen varios factores que se encadenan en el tiempo, a lo que ayuda la prolongada provisionalidad en la ubicación. La documentación da a entender que la administración forestal en la colonia no posee un local en el que ubicarse cuando se desgaja del Servicio Agronómico. ${ }^{26}$ Esto se soluciona temporalmente ocupando dos habitaciones "en ruinas" del antiguo

23 AGA 81/6410

24 AGA 81/8150; 81/6410; 81/12257

25 Pascua y Guerra, 2017. En el primer tercio del siglo XX, España es un país netamente importador de madera. Como media, compra en el extranjero aproximadamente el 50 \% de la madera que consume a pesar del fuerte incremento de la producción interna como consecuencia de la ampliación de la superficie de montes ordenados (Zapata, 2001). Un informe elaborado por la Asociación de Ingenieros de Montes en 1931 es bastante expresivo de lo que se espera de las selvas de la Guinea en esos años: hacer innecesaria la importación de un millón de $\mathrm{m}^{3}$ al año de madera en rollo o escuadrada, de $600.000 \mathrm{~m}^{3}$ de leñas para su transformación en carbón vegetal y de 300.000 m³ para la elaboración de pasta de papel (AGA 81/6843). En el primer franquismo, el consumo de madera experimenta una intensa subida que es acompañada por una drástica reducción de las importaciones (Zapata, 2001). La imagen de las selvas de la Guinea continental española como un espacio de provisión rebasa cesuras históricas: si antes de 1936 permitirían equilibrar la balanza comercial, después de 1939 harían posible, en lo forestal, la política autárquica española

26 AGA 81/8151 
y "desahuciado" hospital de Bata hasta que al cabo de unos meses se encuentra un emplazamiento: el conjunto formado por la casa de la policía y la cárcel indígena. Ambas construcciones, levantadas con nipa y corteza, continúan en pie hasta 1935. En ese momento el Servicio se traslada a Río Benito -lugar más adecuado para el control administrativo de las concesiones forestales- y allí se acomoda en la antigua Casa de Gobierno, un caserón de madera de 1900 y que en 1939 es inhabitable debido a la pudrición de toda su viguería. ${ }^{27}$ Las tribulaciones domésticas finalizan años más tarde con la construcción de un pequeño edificio al que se le adosan progresivamente almacenes y locales para otras instalaciones (Figura 2). En otra ubicación se levanta un "patio" colonial para las viviendas de los braceros contratados por el Servicio Forestal. ${ }^{28}$

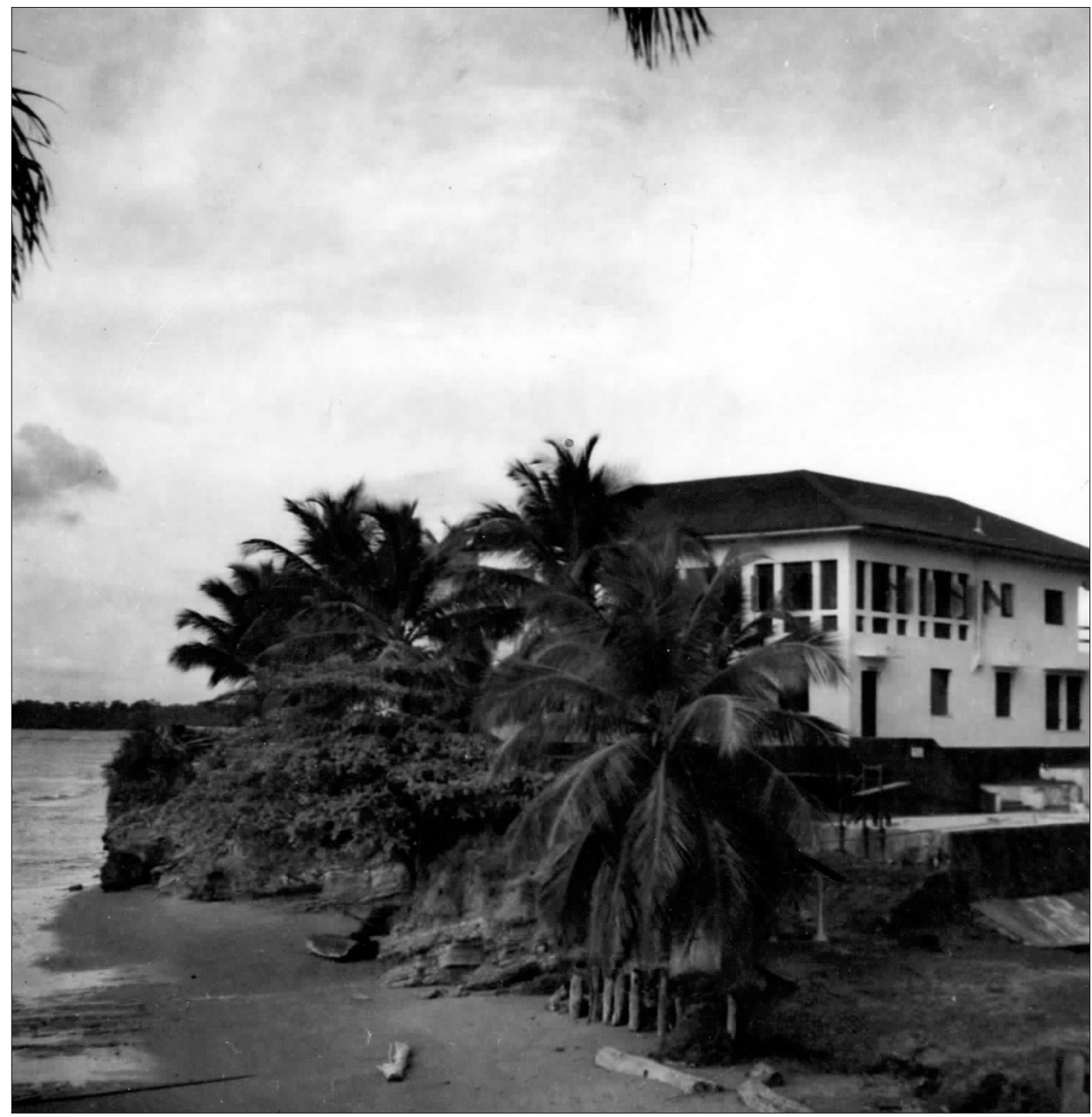

Figura 2. Oficinas del Servicio Forestal hacia 1957

Fuente: Colección de Arturo Sáez Baz. Cortesía de Ester Sáez Pombo

Otros factores se convierten en estructurales. El principal es la escasa continuidad en la dirección del Servicio Forestal. Los recursos humanos con los que trabaja la administración forestal se incrementan de manera significativa a partir de los primeros años de la década de 1940. El tándem ingeniero jefe/ayudante de montes 
que caracteriza los primeros años del trabajo del Servicio se amplía con la dotación de una segunda plaza de ingeniero de montes y, sobre todo, con la aparición de la figura del dasógrafo -llegó a contar con cuatro entre 1950 y 1968. A este núcleo se le añade en 1941 el trabajo del preparador microfotográfico -transformado poco después en una plaza de químico y ocupada hasta la descolonización por Luciana González, aparentemente la única mujer que trabaja en el Servicio- y los de capataz forestal, carpintero y entre 1963 y 1968 el de Guarda Forestal.29 El Servicio Forestal contrata a lo largo de su existencia un número variable de nativos, el grueso de ellos como braceros - 2 en 1931, 30 en 1947, 25 en 1952 y 19 en 1965-. El resto, entre 7 y 9 personas, trabajan como prácticos en maderas, prácticos soldadores, ordenanzas, conductores y oficios varios.30 Hasta que se dota la plaza de guarda forestal en 1965, esta función, con el título de guarda mayor, la realiza el personal militar europeo de la Guardia Colonial. Por último, se prescinde de la figura de ayudante de montes durante casi quince años - de 1943 a 1958- por considerarla innecesaria los distintos ingenieros jefes que se suceden en ese período.31

De 1950 a 1959 el Servicio queda encuadrado en la Dirección de Colonización y se transforma en una de las dos secciones con las que cuenta: agronómica y forestal. Esto hace que se le dote de un solo ingeniero de montes frente a los dos que tiene hasta entonces y que vuelve a tener a partir de 1960. Contando el tiempo de sección, por la jefatura de la administración forestal en la colonia pasan en treinta y nueve años ocho ingenieros. La presencia del infortunio en forma de accidentes de tráfi$\mathrm{Co}^{32}$, las equívocas relaciones con las compañías concesionarias ${ }^{33} \mathrm{o}$ la dificultad para responder a lo que la administración colonial espera de ellos ${ }^{34}$ acortan el tiempo de servicio de determinados ingenieros de montes en la colonia. A diferencia de otras metrópolis, el trabajo en Guinea no constituye para determinadas funciones una carrera profesional autónoma. ${ }^{35}$ Más bien forma parte de otra que se consolida en destinos con mayor atractivo, sobre todo si se tiene en cuenta el sistema de acceso al cuerpo de ingenieros de montes y que a lo largo del período estudiado éstos protagonizan la intensa transformación industrial y capitalista del espacio forestal español. ${ }^{36}$

Más interés posee ver cómo la relación entre puestos de trabajo y funciones responde a la cristalización de una determinada administración forestal. Poco después del informe de Carrera, el primer ingeniero jefe del recién creado Servicio Forestal esboza el modelo que cree más conveniente para la colonia. El objetivo declarado es superar el conocimiento epidérmico que en 1930 se tiene del Muni y

29 Luciana González se licencia en ciencias físicas en 1929 y en farmacia en 1937 (Archivo de la Universidad Complutense de Madrid)

30 AGA 81/8151; 81/6808; Dirección General de Marruecos y Colonias (1949 y 1954)

31 AGA 81/12257

32 El Día, 4 de agosto de 1931 y La Guinea Española, nº 1197, 10 de junio de 1945

33 AGA 81/8647; 81/12421

34 AGA 81/12257

35 Giorgi, 2012

36 Sanz, 1986; Gómez y Mata, 1992; Zapata, 2001; Pemán, Iriarte y Lario, 2017 
proceder a la conquista productiva de su interior. Dicho modelo debe contemplar los aspectos administrativos y fiscales de la explotación colonial del bosque junto con la dotación de personal suficiente para la realización de ensayos silvícolas, labores de reconocimiento e inventario forestal, levantamientos topográficos y control del territorio. ${ }^{37}$ Estas ideas son reelaboradas en ese mismo año por el asesor de montes de la Dirección General de Marruecos y Colonias con la redacción de un informe que es reutilizado a comienzos de 1936 por la Inspección General de Colonias para su tramitación y aprobación. Sin embargo, el comienzo de la Guerra Civil impide que supere la fase inicial de revisión por parte del resto de los servicios de la colonia. ${ }^{38}$ De haber concluido su tramitación y hecho efectivos sus contenidos, preveía articular el servicio en torno a nueve secciones: concesiones, flora y mapa forestal; inspección, aprovechamiento y guías de exportación; laboratorios semi-industriales; silvicultura; estadística y estudios económicos; publicaciones, semillas y conferencias; caza y pesca continental; ordenación y vías de saca terrestres y fluviales y, por último, guardería. ${ }^{39}$

No hay constancia de que con posterioridad se retome la idea de reformular el Servicio, más allá de su subordinación orgánica a la política de "colonización" que se produce entre 1950 y 1959, y como el proyecto de 1936 no llega a traducirse en una norma, parece razonable pensar que no es la voluntad política, sino la práctica diaria la que acaba dándole forma. Ésta gira en torno al control fiscal, administrativo y territorial de las concesiones forestales -a lo que se destina el trabajo del ingeniero de montes, del ayudante de montes mientras existe, de los dasógrafos y de la guardería forestal- y a la caracterización técnica de las maderas de Guinea: una función en la que confluyen el preparador microfotográfico, la química, el carpintero y el capataz forestal del Servicio.

Es este marco el que permite entender el engarce entre práctica forestal y proyecto colonial en la Guinea continental.

\section{Los otros productores de conocimiento forestal colonial}

En el informe que Carrera elabora en 1928 defiende la colaboración amplia de ingenieros, industriales y colonos. Este deseo genérico lo concreta en dos acciones: la participación del Instituto Nacional de Experiencias Agronómicas y Forestales y la realización urgente de una misión forestal que haga un primer cálculo de las posibilidades madereras del Muni. ${ }^{40}$ Ambas propuestas cristalizan en la Real Orden de 31 de julio de 1928 por la que se nombra una comisión de dos ingenieros de montes y un capataz forestal para la confección, a lo largo de seis meses, de un estudio que debe incluir un avance del cálculo de la riqueza maderera, la posibilidad de promover industrias que la aprovechen y la caracterización físico-mecánica de "las maderas susceptibles de emplearse en ebanistería y construcción y especialmente de aquellas

37 AGA 81/6410

38 AGA 81/8150

39 AGA 81/8150

40 AGA 81/6464 
que puedan sustituir a las especies forestales que actualmente se importan". ${ }^{41}$ Las personas nombradas para integrar la comisión son Manuel Carrera, Laureano Saracho -el capataz forestal de la oficina forestal,- y el ingeniero de montes Fernando Nájera, encargado del Laboratorio de la Madera en el Instituto Nacional de Experiencias Agronómicas y Forestales (Figura 3). ${ }^{42}$

En 1930 Nájera publica una parte de los resultados de la misión forestal. ${ }^{43} \mathrm{El}$ grueso del texto gira en torno a la descripción fisiográfica del Muni y a la presentación de las características de la selva. El cálculo de existencias, dada su dificultad y la provisionalidad de los resultados, no se extiende más allá de un par de páginas. El acento lo pone en las utilidades industriales de las maderas de la colonia. ${ }^{44}$ La relación de Nájera con Guinea se mantiene en el tiempo, pero no hay datos suficientes, más allá de una comisión que visita la colonia en 1945 con el objeto de estudiar diversas patologías de la madera y de alguna consulta que se le hace más adelante, para valorar la intensidad y permanencia de los vínculos que se establecen con el Instituto. ${ }^{45}$ En cualquier caso, no parece que fueran relevantes.

Tampoco lo son con el principal productor de conocimiento forestal en España a lo largo del período colonial: la Escuela de Ingenieros de Montes de Madrid. La consulta de sus fondos -la mayor parte desapareció la final de la Guerra Civil- y los del AGA sólo permiten afirmar que esa relación, si existió, fue liviana. No parece que haya una formación geobotánica o silvícola que presente al futuro ingeniero los problemas técnicos de la selva más allá de unas nociones generales, -razonable por otro lado entendiendo que era una ocupación marginal en el conjunto del cuerpo de ingenieros de montes-. Además, en treinta años, de 1939 a 1969, sólo son tres los proyectos fin de carrera que estudian algún aspecto de la explotación colonial. Dos abordan el funcionamiento productivo de las concesiones forestales y un tercero, coincidente en el tiempo con ese mismo discurso en los ambientes forestales coloniales, se adentra en los problemas de regeneración de la selva. ${ }^{46}$ Un buen ejemplo del reducido interés técnico que despierta la Guinea continental entre los ingenieros de montes lo proporciona el análisis de los artículos que

aparecen en su órgano oficioso de expresión: la Revista Montes. De 1901 y 1927, año en el que se interrumpe su publicación durante casi dos décadas, el Muni que hace acto de presencia en las páginas de la revista es aquél del que se puede esperar forestalmente todo con el concurso técnico de los ingenieros del ramo. Es un discurso esencialmente político. A partir de 1944 la revista se publica de nuevo

41 AGA 81/6859

42 Paradójicamente, según el relato que realiza Nájera, el promotor de la idea y primer interesado, Carrera, no presta una suficiente colaboración en el desarrollo de la misión, a la vez que tampoco tiene un destacado interés por los resultados (AGA 81/6859)

43 Nájera, 1930

44 Nájera, 1930; IFIE, 1929

45 La Guinea Española, año XLI, no 1203; Revista Montes, 1945, 3, 162; AGA 81/12257

46 González Aldama, 1950; Romero, 1963; Royo, 1969 
y recoge algunas noticias sobre la evolución de la producción de madera y tres artículos, publicados respectivamente en 1945, 1954 y 1955, referentes a la palmera de aceite, un cultivo del que durante un tiempo se debate quién es el competente en su promoción y gestión: el servicio agronómico o el forestal. ${ }^{47}$ Faltan no sólo cuestiones de economía forestal y aplicaciones técnicas de las maderas coloniales, sino también cualquier referencia vinculada con la silvicultura de la selva. En 1958 aparece la última referencia a Guinea.

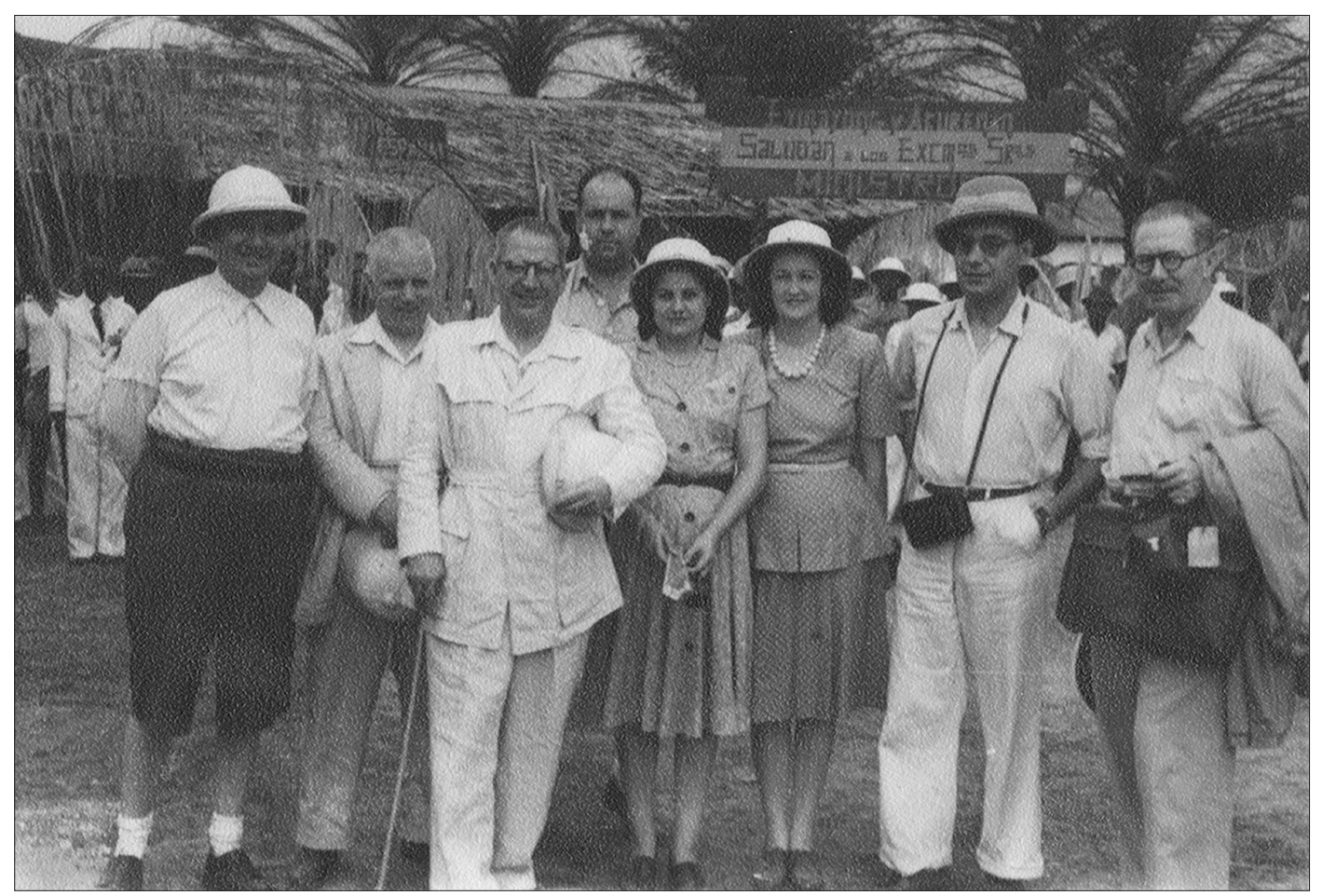

Figura 3. Fernando Nájera, primero por la derecha, en la comitiva que acompaña a los ministros de aire, agricultura e industria y comercio en su visita a la Guinea continental en enero de 1949 Fuente: Cortesía de Fernando Nájera García-Segovia

Por otro lado, el texto de Nájera de 1930 indica la oportunidad de la colaboración con la Cámara Agrícola y Forestal de la Guinea continental. ${ }^{48}$ Creada poco antes, incorpora en su ideario fundacional la producción y transmisión de conocimiento forestal "canónico". ${ }^{49}$ No lo hizo en ningún momento, a pesar de la existencia de un ámbito en el que de manera natural podría haberlo hecho: la empresa y la concesión forestal. La no conservación de los archivos de las sociedades que obtuvieron concesiones forestales en Guinea hace que algunos aspectos de su funcionamiento sólo puedan ser estudiados a través de fuentes indirectas. La documentación del AGA permite recomponer, por ejemplo, sus estrategias comerciales, territoriales y corporativas, pero es más lábil en el entendimiento técnico de la relación que establecen con la selva. En cualquier caso, no parece

47 Foxá, 1945; Ortega, 1954 y 1955

48 Nájera, 1930

49 Guerra y Pascual, 2017 
que el tiempo altere la lógica extractiva que se instala desde el primer momento en la explotación maderera, a la vez que tampoco los problemas que las empresas concesionarias deben resolver. Éstos se resumen en la identificación de los árboles de interés comercial que pueden ser aprovechados y en la planificación eficiente de las vías de saca para su evacuación rápida y económica hasta las instalaciones de primera transformación en la colonia o los puntos de embarque. La selva se reduce a un problema esencialmente logístico, en el que el grueso de los factores de producción -material de las explotaciones forestales, fuerza de trabajo y conocimiento- confluye en su resolución.

La presencia de ingenieros de montes en la dirección del negocio forestal o en los trabajos de explotación en la colonia es marginal. Consta que Octavio Elorrieta asume durante un tiempo la dirección general de la Compañía Agrícola e Industrial de la Guinea Española -CAIGE- y que Fernando Nájera viaja a la colonia y desempeña funciones para la misma compañía en 193250; pero ambos hechos están más en relación con un intento de reorganización productiva de la sociedad dados sus malos resultados de explotación, que con una nueva práctica en el trabajo en la selva..$^{51}$

A finales de 1954, el Gobernador General transmite a la Dirección General de Marruecos y Colonias que no "se permite la explotación de ninguna concesión a no ser que tuviera su correspondiente proyecto de explotación confeccionado por un técnico con capacidad oficialmente demostrada para ello".52 Ha sido imposible localizar estos proyectos o cualquier diligencia de validación, por lo que no se puede tener una idea aproximada ni de su contenido, ni de los conocimientos sobre los que se redactan o de su autoría.

\section{Medida, renovación, beneficio y regulación en las selvas de la Guinea continental}

La silvicultura científica se construye en torno a los conceptos que encabezan este epígrafe. Desde un punto de vista ideológico, sirven para afirmar su modernidad frente a las prácticas precedentes y para dotar de significado a la función que se autoasigna la ciencia de montes. La defensa de su superioridad cultural es una constante en la ciencia forestal europea hasta tiempos recientes. Esto se traduce en la aparición de no pocos conflictos que tienen su origen en la escasa comprensión de los modos de vida de las comunidades rurales y de los aprovechamientos tradicionales del bosque. Si este hecho permite reconocer la existencia de una brecha entre objetos que culturalmente están próximos, no es de extrañar que en el contacto con la colonia esa brecha se ensanche hasta la magnitud del abismo. La cuña que la agranda no es sólo la de la autoridad del discurso técnico, sino

50 Montes e Industrias, noviembre de 1932; Gaceta de Madrid n 141, 20/05/1932; Centro Documental de la Memoria Histórica (CDMH), fondo Político-Social-Documentación particular, caja 192

51 Pascual y Guerra, 2017

52 AGA 81/12257 


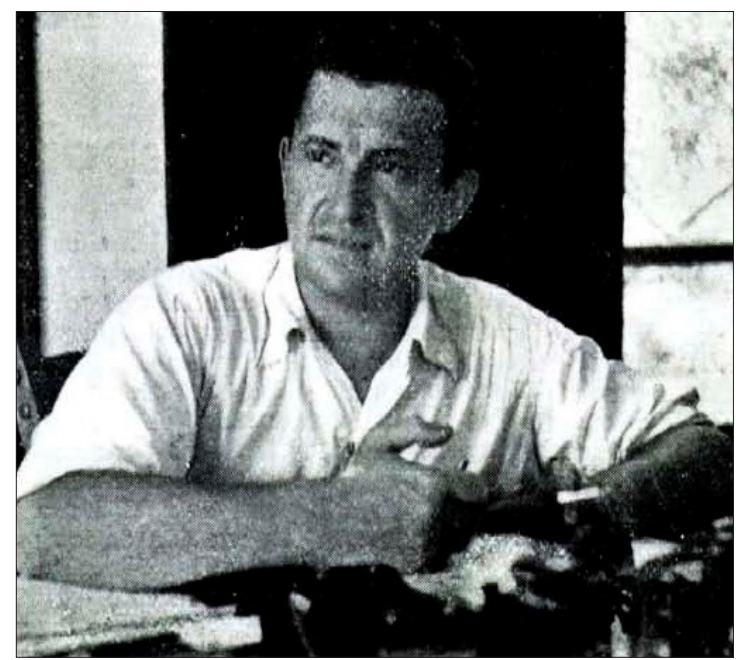

Figura 4. Pedro Fuster Riera, ingeniero de referencia en los trabajos del Servicio Forestal Fuente: Revista Montes, n 147, 1945

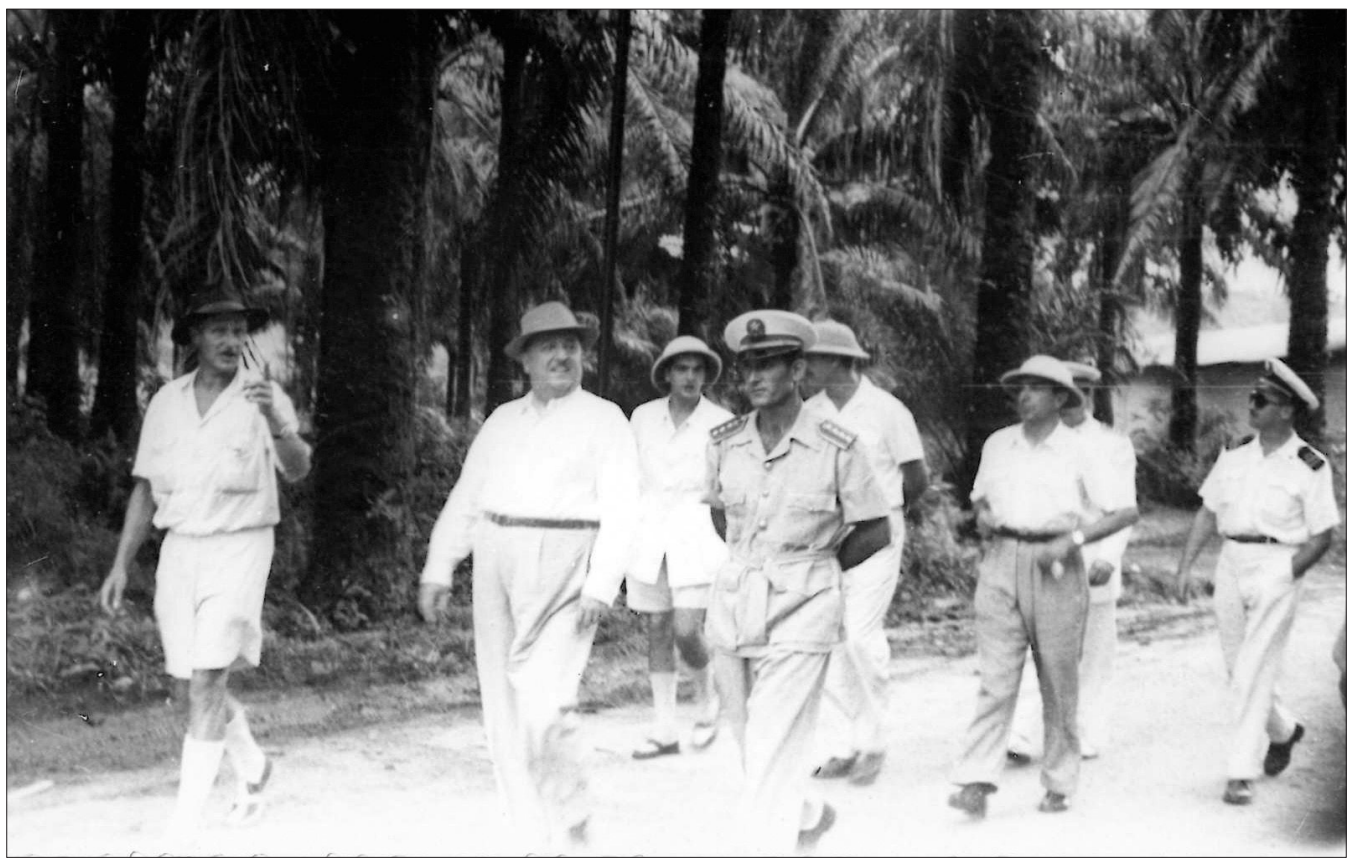

Figura 5. Juan Manuel Capdevielle acompañando al gobernador Faustino Ruiz, primero y segundo por la izquierda respectivamente, en una visita a las instalaciones de SOCOGUI a principios de década de 1950

Fuente: Colección Juan Manuel Capdevielle

también la de la superioridad civilizatoria que se autoconfiere el europeo. ${ }^{53}$ Cabría esperar que en la explotación colonial de las selvas de Guinea se desplegaran todos los elementos sobre los que se construye la silvicultura científica. Como formulación completa, esos principios no rebasan el ropaje con el que se envuelve a determinados discursos. ${ }^{54}$ En su aplicación, la experiencia demuestra que no todos son existieron.

\section{Ribot, 2011}

54 Bonelli, 1945. Bonelli, Gobernador General entre 1943 y 1949, alude a que todos los montes de la colonia están ordenados 
A la lectura silvícola de la documentación administrativa colonial se le suma la científica que pone el acento en los problemas técnicos que origina la explotación de la Guinea continental. En esta última confluyen los trabajos de Fernando Nájera, Pedro Fuster, Juan Manuel Capdevielle y Luciana González (Figuras 4 y 5). ${ }^{55}$ La suma de ambos ámbitos permite esbozar cómo se imbrican medida, renovación, beneficio y regulación en el Muni a lo largo del período colonial.

\section{La medida}

El cálculo de la madera disponible se puede abordar en dos escalas. Una que hace referencia a las posibilidades de la Guinea continental y otras más operativa, relacionada con la gestión del artefacto territorial que canaliza la extracción de madera: la concesión forestal. La primera de las vías ya ha sido expuesta en trabajos anteriores, no así la segunda. ${ }^{56}$

La medida nace con el inventario; y éste encuentra severas dificultades para su realización derivadas de la complejidad estructural de las distintas "selvas" que conviven en la Guinea continental y del objeto que se inventaría. De hecho, no se trata de un inventario que muestre el estado natural del territorio que se explota, sino de la localización y una somera caracterización dendrométrica de los pies de las especies con mayor interés comercial. Éstos suponen una proporción reducida de todas las presentes en la selva, aunque creciente en número conforme se conocen mejor sus propiedades técnicas y usos posibles. Además, todas estas especies comparten una característica: su escasa representación por unidad de superficie.

El inventario es anterior a la explotación y resulta trascendente para ella: como reconocimiento orienta las grandes líneas de la ocupación forestal de la colonia y como localización de pies apeables guía el frente de avance de la saca de madera en cada concesión forestal. ${ }^{57}$ Dado que en realidad es una entresaca de ciertos árboles,

su correcta localización es determinante para la ubicación y conexión de los apiladeros por los que circulan las trozas de madera antes de ser embarcadas rumbo a la península, racionaliza el uso de los factores de producción al servicio de la empresa forestal y de la explotación colonial de la selva (figura 6).

Junto a la discusión sobre los anchos de vía adecuados para los ferrocarriles forestales que se tienden en la Guinea continental, el correcto uso del tractor de orugas, las posibilidades del camión como medio de transporte o el uso del material de arrastre, aparece el debate sobre los métodos de inventariación más adecuados. Una realidad los condiciona. Las espesuras derivadas de los distintos estados de rege-

55 Pedro Fuster finaliza sus estudios de ingeniero de montes en 1931 y se incorpora al Servicio Forestal de los Territorios Españoles del Golfo de Guinea en 1935. A él se debe en realidad la organización del servicio y los trabajos de más calado desarrollados en la colonia. En cuanto a Juan Manuel Capdevielle, una reciente e interesante reseña sobre su vida y obra es la elaborada por Luengo (2017)

56 Guerra y Pascual 2015b y 2017

57 Capdevielle, 1947 y 1949 


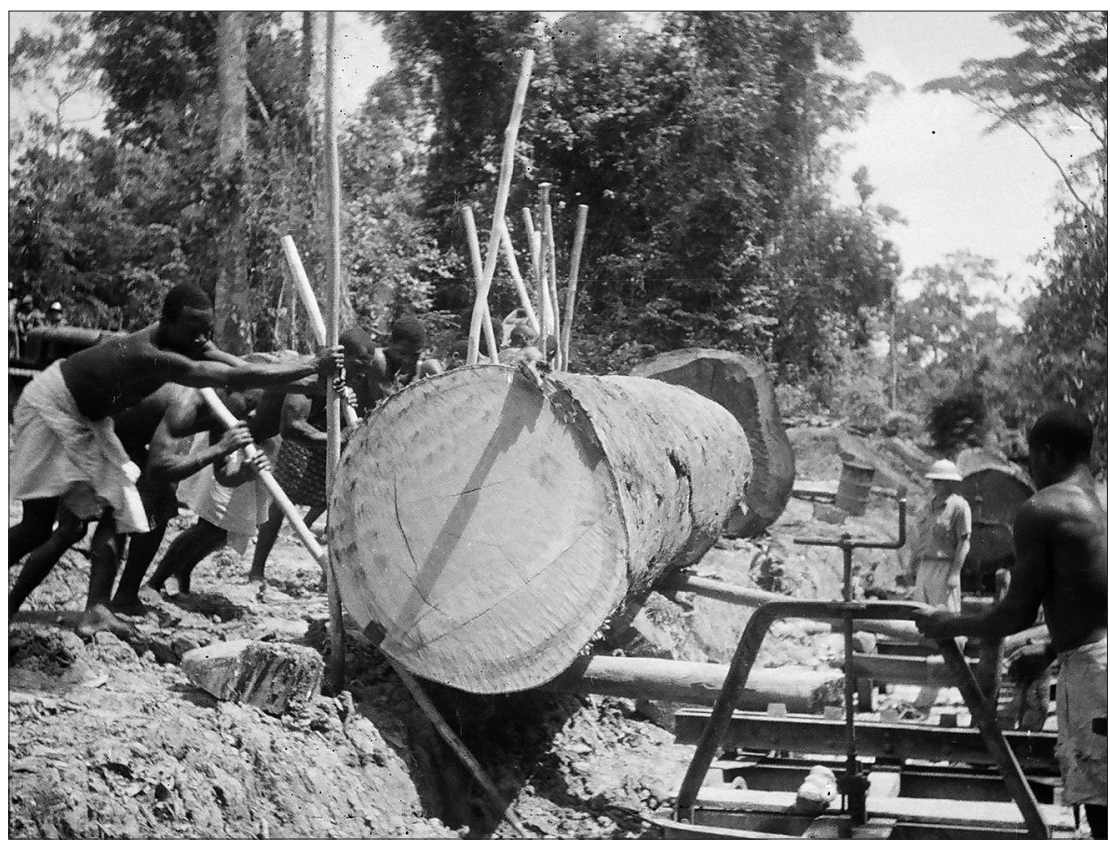

Figura 6. Trasiego de las trozas de ocume entre el apiladero temporal en la selva y el ferrocarril forestal. Mediados de la década de 1940

Fuente: Manuel Hernández-San Juan-Hérmic Films

neración de la selva hacen extremadamente lento y antieconómico el reconocimiento de la superficie de cada explotación. Es necesario discurrir un procedimiento que permita adquirir una imagen razonablemente certera de las posibilidades de una concesión forestal una vez que ha sido otorgada..$^{58}$

Es por eso, que Capdevielle ve oportuno que las empresas proporcionen al servicio forestal detalles planimétricos y numéricos de los inventarios madereros de las concesiones. ${ }^{59}$ Por tanto, se puede concluir que la administración no dispone en ese momento de una información comparable a la que utilizan las empresas concesionarias, aunque también es cierto que no parece que la buscase. El trabajo del Servicio Forestal se centra más en el reconocimiento general de la colonia, en la determinación de las grandes magnitudes de las posibilidades maderables, que en el inventario forestal en sentido estricto. Todos los proyectos que, con más o menos grado de elaboración, se redactan en sus primeros años de vida con el objeto de definir su estructura y el encargo que recibe incorporan esta actividad. ${ }^{60}$ Es difícil valorar cómo se lleva a cabo, con qué grado de extensión, intensidad y continuidad. Un informe elaborado por Fuster en febrero de 1936, poco después de incorporarse como ingeniero en la administración colonial, proporciona datos en este sentido. El reconocimiento tiene una intencionalidad: dirigir "la cesión a particulares de superficies de conocida abundancia maderera". A su vez, cubre una necesidad, ya que seis años después de creado el servicio se

58 Fuster, 1941; Capdevielle, 1949

59 Capdevielle, 1947, 33

60 AGA 81/6410 y 81/8150 
"carece de datos de las zonas no explotadas, siendo preciso hacer un reconocimiento mediante exploraciones sucesivas que permita reconocer con la aproximación requerida, las características forestales de una zona elegida". ${ }^{61}$

Para la ejecución del reconocimiento de unas 50.000 Has en el oeste de la Guinea continental, propone realizar inventarios perpendiculares a la dirección de avance de 250 metros de longitud por cada kilómetro recorrido. En total, más de siete meses de trabajo campo (Figura 7). ${ }^{62}$

De alguna forma, estas prospecciones continúan con objetivos diversos hasta el momento de la descolonización. En el procedimiento sancionador que se le abre a mediados de los años cuarenta a León Cardenal por irregularidades en la gestión del Servicio Forestal aparecen referencias a reconocimientos de la selva y al bosquejo del área ocupada por cultivos de interés, como los palmerales de la región de los Bimbiles. ${ }^{63}$ Por otro lado, una biografía del guarda forestal Domingo Fontenla, increíblemente fantasiosa en no pocos aspectos, describe con verosimilitud una parte de su trabajo en la Guinea continental: la inventariación de las reservas madereras. ${ }^{64}$ Con independencia de que a finales de los años sesenta el reconocimiento se haya extendido a otros sectores de la colonia, parece que allí donde es más intenso es al occidente del continente, en un amplio sector cercano a la costa, rico en ocume y asiento principal del hecho concesional. La confección del Avance del Mapa Topográfico y Forestal de Guinea -realizado entre 1945 y 1948 y publicado a partir de 1949- es una buena muestra de ello. ${ }^{65} \mathrm{Su}$ confección por parte del Servicio Geográfico del Ejército revela la imposibilidad de la administración forestal para enfrentarse a un trabajo de esa magnitud, pero también el conocimiento que se tiene de la franja litoral en ese momento. De hecho, los diferentes croquis y esquemas que aporta el Servicio Forestal proporcionan a dicha cartografía un nivel de detalle superior al del interior y este de la Guinea continental.

Con su idea de colaboración entre Servicio Forestal y empresas forestales, Capdevielle da a entender que estas últimas cuentan con un volumen de información relevante. Sin embargo, en las obras que escribe dibuja cuando menos una realidad diferente. Por un lado, indica que bastantes de las concesiones se han obtenido sin la realización de ningún inventario o tipo de estudio previo. ${ }^{66}$ Por otro, parece que no son pocas las dificultades para que los inventarios, una vez que comienzan las operaciones de las empresas, aporten un grado de certidumbre suficiente ${ }^{67}$ Ambos

$61 \quad$ AGA 81/8151

62 Atendiendo a los datos que proporciona Capdevielle años más tarde, ese cálculo de tiempo puede ser claramente insuficiente (1949)

63 AGA 81/12421

64 Vila, 2011, 37

65 Guerra y Pascual, 2015b. Las hojas del Avance se publican entre 1949 y 1952, después de

concluir en 1948 unos trabajos que se habían iniciado en 1945

66 Capdevielle, 1947, 35

67 Capdevielle, 1947, 57 


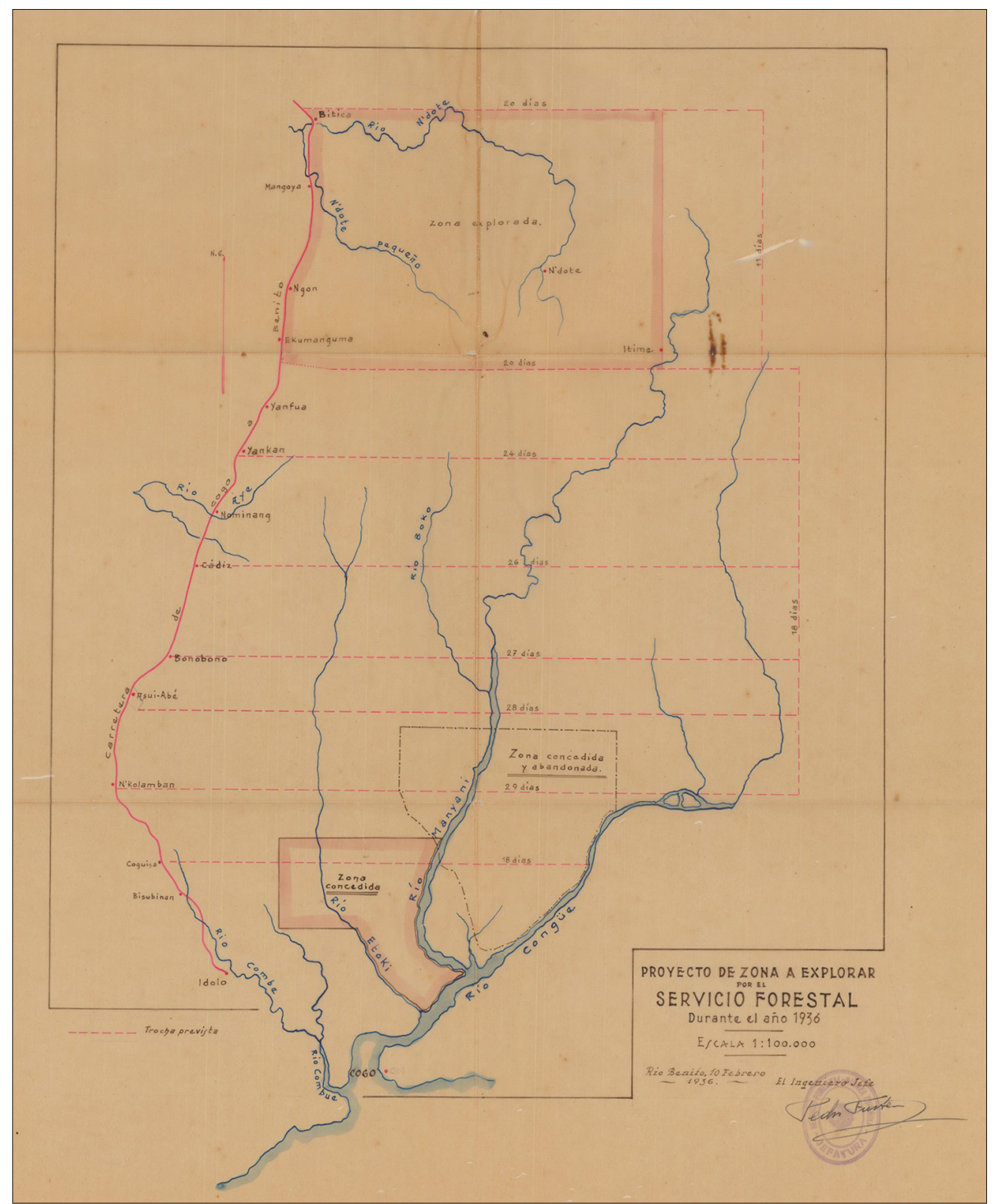

Figura 7. Mapa del proyecto de zonas a explorar por el Servicio Forestal de los Territorios Españoles en el Golfo de Guinea (1936)

Fuente: MECD, AGA, IDD (15) 018.000 Fondo del Gobierno General de Guinea, caja 81/08151, exp.

1.

hechos son relevantes: determinan la rentabilidad esperada de la concesión y su ordenación en zonas.

Un ejemplo de la debilidad de los inventarios que se realizan se extrae de la experiencia de la Compañía Nacional de Colonización Africana (ALENA) en sus concesiones del Río Campo a lo largo de la primera mitad de los años treinta. Estas concesiones necesitan la construcción de un ferrocarril forestal para la evacuación de la madera hasta la playa de Utonde al estar situadas en un punto relativamente adentrado de la colonia. La construcción de la vía férrea, con una longitud de unos 35 $\mathrm{km}$ por terreno accidentado, exige la reorganización financiera de la sociedad. Ésta se aborda en 1932. En ese año, el Banco Exterior de España envía a la Guinea continental a una persona para la realización de un informe confidencial sobre la situación de ALENA. ${ }^{68}$ El observador pretende realizar sus propios inventarios en las concesiones 
de Río Campo con el objeto de valorar el riesgo que asume el banco. Al poco de llegar, se convence de la imposibilidad del encargo. Obligado por la complejidad de la selva, sustituye el inventario por noticias que extrae de conversaciones discretas o de observaciones que obtiene en sus visitas a las instalaciones de la compañía. El resultado es negativo para las pretensiones de ALENA y dispar para la colonia: muestra como ejemplo de buen trabajo los reconocimientos llevados a cabo por la Compañía Agrícola e Industrial de la Guinea Española (CAIGE), pero poco acertados, a pesar de existir, los de ALENA. Ésta dispone de recuentos de existencias, si bien se duda de la validez de sus resultados. ${ }^{69}$ Parece que éstos no incorporan ninguna ubicación de los pies de interés comercial y que su número está sobreestimado por la confluencia de los intereses pecuniarios de quienes realizan los conteos y los comerciales de la compañía.

El hecho de poner como ejemplo Capdevielle los trabajos que él mismo realiza en la Sociedad Colonial de Guinea (SOCOGUI) y en la Compañía Vasco-Africana (VASAFRI) hace pensar que la minuciosidad de los inventarios que propone son una excepción en la colonia a finales de la década de 1940. De hecho, indica que el efectuado en la concesión de SOCOGUI en Cabo San Juan es único en su género y que tan sólo en los últimos cuatro años las empresas han empezado a enfrentarse a este trabajo técnico con mayores medios y convencimiento. Además, en la nueva reglamentación forestal para futuros concesionarios que elabora Fuster antes de su fallecimiento en 1945 se contempla exigir -quizá como muestra de que hasta entonces no se realiza- la confección de un inventario previo de toda la madera comercial existente en cada concesión para poder iniciar los trabajos de explotación. ${ }^{70}$

\section{La renovación y el beneficio}

La existencia de una utilidad, de un mercado para las maderas tropicales, de aplicaciones industriales que proporcionen valor a sus características técnicas es el elemento que determina el volumen directo de madera que la concesión puede extraer. Al igual que en otras colonias, una parte sustancial del conocimiento que la experiencia colonial produce se encamina a la sistematización de las propiedades físicas de la madera y a su comparación con las utilizadas por la industria transformadora metropolitana. El objetivo primario de la expedición en la que participa Nájera en 1929, más allá de las consideraciones que hace de la riqueza forestal de la colonia, es la recogida de muestras y su análisis en el Instituto Forestal de Investigaciones y Experiencias. Es más, las incursiones de Nájera en el forestalismo colonial se enmarcan siempre dentro de ese contexto: el abastecimiento de maderas y las utilidades que se les pueden proporcionar. ${ }^{71}$ Las aportaciones más relevantes de Fuster y González se sitúan igualmente en este ámbito. De hecho, a ellos se debe el grueso del cono-

69 CDMH Ps Documentación Particular, C. 192

70 Capdevielle, 1949, 160

71 Nájera 1948, 1950, 1957 
cimiento de las maderas de la Guinea continental, ${ }^{72}$ más allá de que las empresas forestales también dediquen recursos en este sentido, sobre todo en el campo de la divulgación comercial. ${ }^{73}$

La noción de renovación se acota en la colonia a la pervivencia de las especies de interés comercial. No parece que la actividad maderera comprometa la continuidad de la selva ${ }^{74}$, pero sí que se provoca cambios cualitativos en su composición que dificultan el extractivismo forestal. ${ }^{75}$ Ante la ausencia de otras operaciones culturales, la renovación es la actividad con el perfil más silvícola de cuantas se desarrollan en la selva. No obstante, la ausencia de un cuerpo teórico que le de cobertura hace que sea una silvicultura eminentemente experimental. ${ }^{76}$ Además, gira en torno a una especie: el ocume. Es decir, no es una silvicultura que aporta conocimientos generales sobre el trópico, sino una práctica dirigida exclusivamente a entender las condiciones que facilitan la regeneración y mayor abundancia de la especie que se convierte en el referente del comercio colonial.

En ese entendimiento, aparecen las referencias a autores franceses, e incluso no faltan algunos contactos en la década de 1940 con los técnicos de los servicios forestales franceses en África. ${ }^{77}$ Los conocimientos que fluyen en estas relaciones intercoloniales sirven para decantar la experiencia hacia un tipo de práctica concreta: el enriquecimiento de la selva en ocume. Una vez que, como presupuesto teórico, se abandona por imposible y antieconómica la sustitución de especies -el levantamiento de la selva y la ejecución de plantaciones monoespecíficas de las especies de interés comercial-, se afianza la noción del enriquecimiento. Son seguidos con atención los resultados de los ensayos que se realizan en Costa de Marfil, Camerún y Gabón con el ocume y con especies de temperamento y utilidades semejante. Estos trabajos se pueden seguir a través de la Revue de botanique appliquée et d'agriculture coloniale e et d'agriculture coloniale y, sobre todo, de Bois et Forêts des Tropiques. Se trata de comprender las condiciones que facilitan la regeneración natural o artificial del ocume y los tratamientos culturales que pueden incrementar su frecuencia relativa en la selva. ${ }^{78}$

72 Fuster y González, 1947; González, 1953

73 Capdevielle, 1946; Aggor, 1952

74 Capdevielle, 1947, 30

75 Fuster, 1941, 45

76 Capdevielle, 1949, 59

77 La documentación del AGA hace referencia a algunos contactos de este tipo, aunque no parece que fuese una práctica habitual. En cualquier caso, los forestales franceses son leídos y analizadas críticamente sus aportaciones. Conforman un cuerpo de conocimiento que, junto con algún otro autor, circula por los ambientes forestales de la colonia, sobre todo en los años cuarenta. Es en este momento, como se ha visto, cuando se elaboran los mejores textos forestales sobre la Guinea continental. Capdevielle menciona con reiteración a Aubreville, inspector general de bosques de las colonias francesas, del que extrae noticias sobre métodos de regeneración y repoblación de la selva. Por su parte, Fuster, preocupado por los trabajos de reconocimiento e inventariación, alude a las ideas de Bertin, Foury, Chevalier y Hedinl

78 El ocume (Aucumea klaineana) es una especie de madera blanda que necesita luz para germinación y desarrollo. Se ve favorecido por la apertura de claros de cierta extensión en la selva. Esto hace 
En la primera mitad de la década de 1950, la administración metropolitana traslada a la colonial la necesidad de enfrentarse al problema de la renovación de las existencias maderables en las concesiones forestales. ${ }^{79}$ En realidad, esta preocupación emerge en un momento anterior, temprano. En 1930, poco después de iniciada la explotación forestal intensiva del continente, un informe indica que los concesionarios carecen de "gente entendida en la materia" y que "ni uno solo repuebla ni introduce mejora alguna [...] y el ocumen se reduce cada vez más". ${ }^{80}$ El valor de esta afirmación se incrementa con el tiempo. En noviembre de 1936 se constituye el Sindicato Maderero como agrupación de todos los concesionarios forestales en la colonia. ${ }^{81} \mathrm{En}$ una de sus primeras reuniones se enuncian las tres principales preocupaciones a las que debe hacer frente. Una, al mismo nivel que la situación contable de las empresas o el acceso a la mano de obra nativa, es el agotamiento de las existencias de árboles maderables dentro de las concesiones. ${ }^{82}$

La alusión al agotamiento hace emerger la conveniencia de la repoblación y el discernimiento de cuál puede ser el método más adecuado para llevarla a cabo. Unos años después, Fuster indica que ha podido observar algunos ensayos de las compañías Izaguirre y Jover \& Graells, pero que en cualquier caso no son necesarias las repoblaciones por "acción personal", sino confiar en la siembra y regeneración natural. ${ }^{83}$ Para las colonias francesas de África occidental y ecuatorial, algunos autores sostienen que la defensa por parte de la administración de la repoblación natural se alinea con los intereses de las empresas concesionarias, reacias a efectuar los desembolsos que implica la repoblación artificial. ${ }^{84}$ En el caso de la Guinea continental no se encuentran indicios en este sentido, toda vez que los argumentos técnicos no parecen encubrir ningún otro tipo de discurso, que la administración señala con reiteración que cualquier trabajo repoblador debe ser financiado por las empresas forestales y que éstas, aunque con condiciones, dicen estar dispuestas a enfrentarse a los gastos llegado el momento.

Desde un punto de vista técnico, Fuster y Capdevielle poseen opiniones divergentes. Si el primero confía en la diseminación natural, el segundo pone el acento en el enriquecimiento artificial de la selva. ${ }^{85}$ No obstante, cuando más tarde llega el momento de convertir en norma la experiencia adquirida en la selva, los forestales

que exista una estrecha relación entre la agricultura de roza y plantación nativa -sobre todo de los claros abiertos para el cultivo itinerante de la yuca- y altas densidades de ocume. Su aprovechamiento comercial se produce, aproximadamente, cuando el ocume alcanza los cuarenta años de edad

79 AGA 81/12257

80 AGA 81/6856

81 Boletín Oficial de los Territorios Españoles del Golfo de Guinea, 11-XI-1936

82 El término agotamiento requiere una explicación. En el lenguaje colonial no equivale a la desaparición del conjunto de existencias maderables, sino a las de los individuos de especies de interés comercial -especialmente ocume- con el diámetro legal - $60 \mathrm{~cm}$ - que hace que sean aprovechados.

83 AGA 81/8152

84 Puyo, 2000

85 Fuster, 1941; Capdevielle, 1947 y 1949 
de academia o de práctica no desempeñan una función relevante. El proceso de redacción de la Orden de 30 de marzo de 1954 por la que se aprueba el Reglamento de Repoblación y Conservación Forestal para los Territorios Españoles del Golfo de Guinea resume muchas de las limitaciones en las que se desenvuelve la práctica forestal.

En mayo de 1952, la Dirección General de Marruecos y Colonias remite al Gobierno General un despacho en el que transmite ser "del mayor interés en las explotaciones forestales que se realicen, atender en la medida conveniente a la replantación de árboles en forma gradual, según vayan desarrollándose la explotación". ${ }^{86} \mathrm{El}$ oficio incluye un encargo: redactar a la mayor brevedad posible un proyecto de orden que desarrolle la obligación que se impone a los concesionarios por la Ley de 4 de mayo de 1948 por la que se reforma el régimen de la propiedad territorial en Guinea ${ }^{87}$ y la Orden de 30 de abril de 1951 sobre pliegos de condiciones generales de las subastas forestales dependientes de la Dirección General de Marruecos y Colonias. ${ }^{88}$ Una primera aproximación sale de la colonia a finales de abril de 1953 y el borrador de orden en noviembre de ese mismo año. ${ }^{89}$ La tardanza de más de un año hace necesaria una explicación. Ésta se encuentra, en palabras del Gobernador General, en la "inexcusable negligencia, por no decir incompetencia manifiesta, del último ingeniero de montes". De hecho, ambos documentos los elabora el ingeniero agrónomo jefe de la Dirección de Colonización y no el ingeniero de montes, cesado en abril de 1953.

Con pequeñas variaciones, el borrador se transforma en el Reglamento de Repoblación y Conservación Forestal para los Territorios Españoles del Golfo de Guinea, que se publica como orden en marzo de 1954. Distingue tres tipos de bosque: de aprovechamiento indígena, en explotación y del Estado no sometido a explotación. El primero, definido conforme a lo señalado en la Ley de 4 de mayo de 1948, contempla unos criterios de conservación y repoblación que arropan un objetivo eminentemente político y colonial: la sedentarización de la población. Todo desbosque ha de ser sustituido por un cultivo o plantación permanente, y no se concede ningún otro si el anterior no se encuentra en un buen estado de cuidado.

Los bosques en explotación se sitúan en las concesiones forestales no caducadas. En ellos se concentra el grueso de la normativa que la orden desarrolla. Obliga a que se cuente con un proyecto de explotación (anteproyecto en el caso de concesiones superficialmente extensas) y que los datos de inventario se aporten al Servicio Forestal. También se determinan las especies de interés comercial y los diámetros mínimos con los que pueden ser apeadas. A su vez, se establece que los trabajos de repoblación y conservación sucedan a los de corta y que los dos primeros deben servir para estimular la repoblación natural o propiciar la artificial. Con este fin, todos los bosques en explotación deberán contar con uno o más viveros.

Por último, los bosques del Estado no sometidos a explotación son los no incluidos

86 AGA 81/12257

87 BOE 06/05/1948, n 127

88 BOE 05/05/1951, n ${ }^{\circ} 125$

89 AGA 81/12257 
en ninguna de las categorías anteriores. En ellos, salvo para una concesión agrícola, se impide cualquier tipo de desbosque y la repoblación que se persigue es la natural.

La orden en realidad no es en exceso precisa en sus elementos nucleares. Un informe previo de la Asesoría Jurídica de la Presidencia del Gobierno advierte la falta de concreción en el contenido de los planes de repoblación y conservación, a lo que la Dirección General de Marruecos y Colonias responde "que las palabras repoblación y conservación son lo suficientemente expresivas para fijar su alcance, y no se gana nada, sino más bien puede inducir a confusión, con definirlas en el Reglamento

[...] que los planes tienen que ser muy distintos según los casos, y no es fácil prever en el Reglamento cuáles han de ser las características comunes a todos ellos, y cuáles las específicas; y que [...] hay que confiar en que la Administración no exigirá nunca planes irrealizables o excesivamente onerosos, ni tal riesgo sería evitable con una definición, por muy científica que fuera, de en qué haya de consistir cada plan de repoblación". ${ }^{90}$

No se ha localizado en el AGA documentación suficiente que permita valorar cómo se llevaron a cabo los extremos contenidos en la orden y con qué continuidad en el tiempo. Algunas comunicaciones entre el Gobierno General y la Dirección General de Marruecos y Colonias dan a entender que en un primer momento algún tipo de actividad sí que se desplegó. En los bosques de las concesiones parece que se exige la existencia de un proyecto de explotación, mientras que en los indígenas la Dirección de Colonización y administradores territoriales impiden cualquier nuevo desbosque si quien lo solicita no reúne, a su juicio, los criterios indicados en la orden. Por otro lado, se da a entender que al vivero que el Servicio Forestal en Río Benito se le suman otros en las granjas avícolas que la sección agronómica posee en distintos poblados.

Es revelador que el elemento central de la orden -los trabajos de repoblación y conservación- sea objeto de discusión más de dos años después de aprobada. A diferencia de otros preceptos que se entienden como un mandato, éstos necesitan de deliberación, de acuerdo y de investigación silvícola previa. La Dirección de Colonización informa en noviembre de 1955 que son 45.000 las hectáreas repobladas desde el comienzo de la explotación forestal de la colonia. En marzo de 1956, indica sin embargo que el volumen de superficie repoblada artificialmente es nulo. La primera cifra es probable que se refiera a aquella superficie que, en un cálculo generoso y contradictorio con todas las informaciones anteriores, se considera repoblada de forma natural. En cualquier caso, la investigación en repoblación artificial llega tímidamente con la incorporación del ingeniero Arturo Sáez a la sección forestal de la Dirección de Colonización (Figura 8). Éste pone en marcha un conjunto de parcelas de experimentación con las que prevé la "forma de comportarse de aquellas esencias forestales que actualmente tienen un interés comercial" y novedosamente "el estudio de las especies más recomendables para la conservación del suelo" (Figura 9).91

90 AGA 81/12257

91 AGA 81/12257 


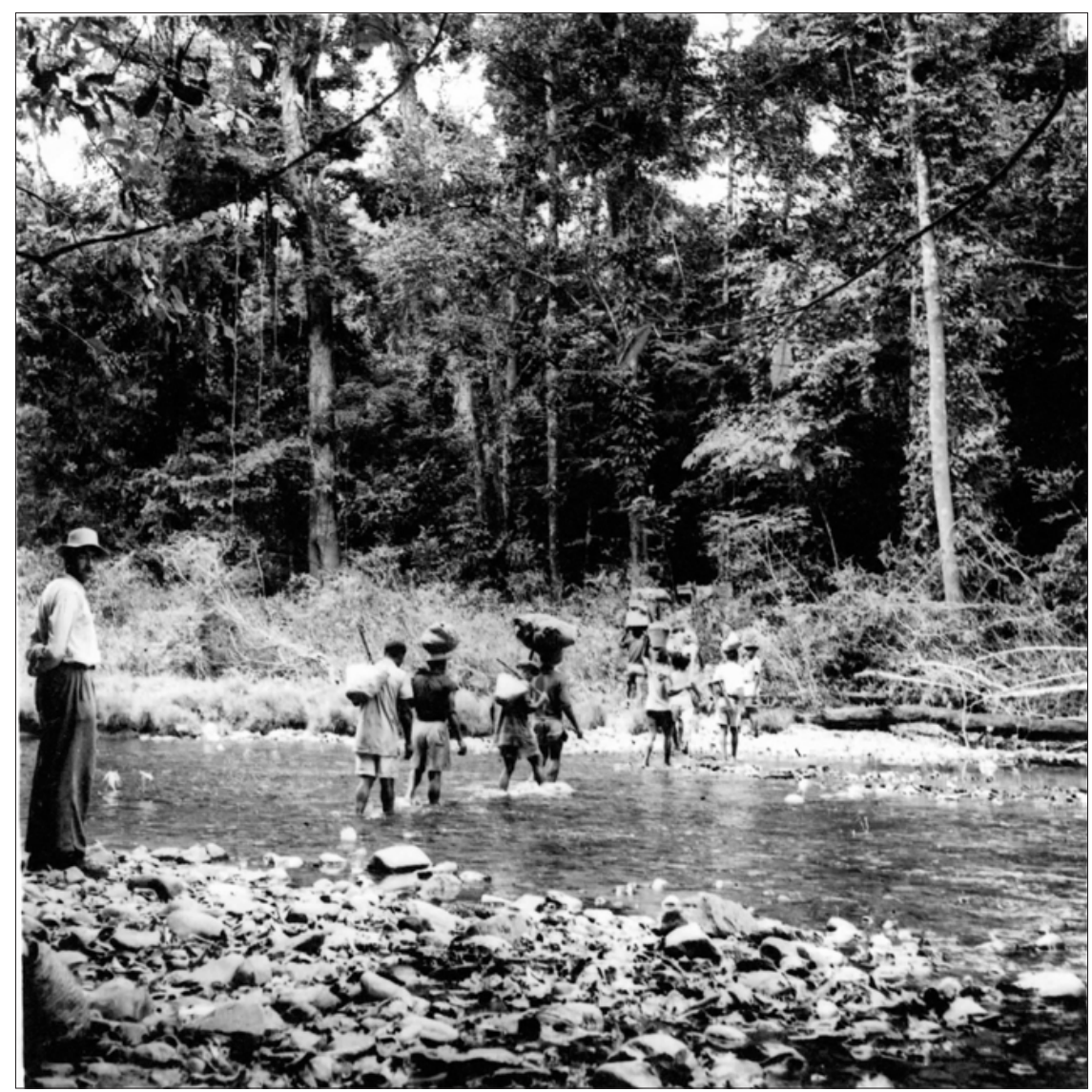

Figura 8. Arturo Sáez en un recorrido por la selva con los braceros del Servicio Forestal. Finales de la década de 1950

Fuente: Colección de Arturo Sáez Baz. Cortesía de Ester Sáez Pombo

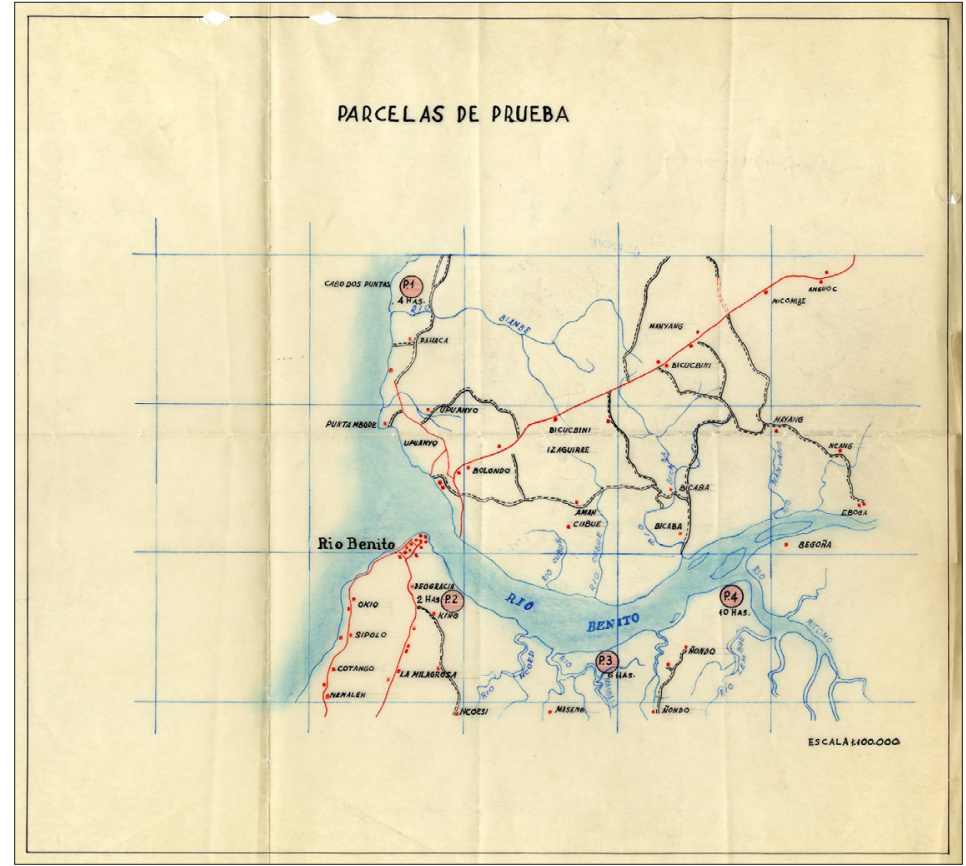

Figura 9. Plano de parcelas de experimentación forestal del Servicio Forestal de los Territorios Españoles en el Golfo de Guinea (ca. 1954)

Fuente: MECD, AGA, IDD (15)006.000 Fondo de la Dirección General de Plazas y Provincias Africanas, caja 81/12257, exp. 641-14. 
Una vez encaminado en apariencia el discurso silvícola, se afronta la relación con las empresas forestales. La interlocución se establece con la Delegación Peninsular del Sindicato Maderero; pero el interés que la dirige dista bastante de ser el de la mera repoblación de la selva. En un momento que coincide con la intensificación del extractivismo forestal que se practica en ella y la adjudicación de nuevas concesiones, los empresarios ya instalados en la colonia proponen a la administración metropolitana un procedimiento que presuponen ventajoso para ambos: encomendar los trabajos de repoblación al Servicio Forestal, financiarlos en una proporción determinada por cada hectárea de concesión y obtener a cambio nueva superficie explotable sin ningún trámite previo de subasta o concurso, libre de toda obligación a repoblar.92

La documentación, el cruce de propuestas y recibís, se interrumpe a finales de octubre de 1956. El desarrollo posterior del hecho concesional no pone de manifiesto que la intención de los integrantes del Sindicato Maderero de asegurarse una posición ventajosa en el nuevo reparto de los recursos maderables de la colonia sea tenida en cuenta. Tampoco el que las repoblaciones se lleven a cabo.

\section{La regulación}

Además de renovar es necesario regular el aprovechamiento de la selva. La legislación de 1904 sobre propiedad territorial de la colonia establece quién puede acceder al negocio forestal, cómo debe circular la madera desde la corta al embarcadero y qué cánones se deben satisfacer. A su vez, los pliegos de adjudicación de las concesiones fijan obligaciones productivas y repobladoras, además de las infracciones derivadas de su incumplimiento. Al volumen mínimo de madera que se debe extraer por hectárea, se le añade el compromiso de corta a hecho de una superficie de la concesión. El terreno noval debe ser repoblado artificialmente con palmeras de aceite o con árboles de caucho. Por último, por cada árbol apeado, conforme a unos criterios de diámetro mínimos, se deben plantar veinte árboles jóvenes. Cuando en la década de 1950 surja el debate sobre el agotamiento de las reservas maderables de ocume, estas prescripciones son corregidas y territorializadas conforme a un criterio más amplio.93

El aprovechamiento que la lógica colonial institucionaliza entra en colisión con otro que deslegitima: el uso que el nativo hace de la selva. ${ }^{94}$ Para el forestal europeo, la agricultura de roza y plantación es, a pesar de admitirse la estrecha relación que existe entre ella y los sectores en donde el ocume es más abundante dadas sus exigencias de luz, la principal perturbación que compromete la viabilidad de los regenerados de esa especie. ${ }^{95} \mathrm{~A}$ su vez, se limita el uso que puede hacer de la madera, restringido a necesidades domésticas, construcción de canoas y cabañas. Por otro lado, a cada poblado se le asigna, en función del número de familias, una superficie de selva a la que queda permanentemente vinculado.

92 AGA 81/12257

93 AGA 81/12257

94 Guerra y Pascual, 2017

95 Capdevielle, 1947 


\section{Conclusiones}

La presencia colonial española en las selvas de Guinea Ecuatorial muestra cómo la extracción de madera se convierte en un negocio sostenido en el tiempo sin el concurso de un elaborado discurso técnico y de una práctica equivalente que lo acompañe. Ni el ejercicio del poder colonial, ni el extractivismo forestal los necesitan. Esta afirmación se puede enunciar de otra manera. Los conocimientos forestales que se trasladan a la colonia redefinen su semántica en contacto con ella. Se seleccionan algunos conceptos nucleares y se les dota de otro significado con independencia de que no se abandone la retórica de la aplicación de la ciencia. El léxico forestal es el mismo; los contenidos divergen sustancialmente.

Medida, renovación, beneficio y regulación no poseen el mismo significado en la explotación colonial del bosque que en la de los montes de la Europa templada. Otras metrópolis hacen frente a la práctica de la silvicultura tropical con el desarrollo de una variada actividad técnica. En el caso español, esto no ocurre con la misma intensidad. Al negocio forestal se le desnuda de todo aquello que no responde a una necesidad inmediata. El conocimiento que se construye gira en torno a la explotación forestal y tiene como núcleo el desplazamiento físico de la madera: hacerlo económicamente eficiente desde el apeo del árbol hasta el embarque de la troza. A ese conocimiento se añaden los restantes, como es el caso del inventario, esencial para organizar correctamente las vías de saca y la entidad de los medios de arrastre que circulan por ellas. Por otro lado, el beneficio no depende tanto de la perdurabilidad de la masa como de la ampliación del número de especies aprovechables industrialmente, algo que ocurre a partir de 1940. Y la renovación se entiende en la práctica como un ejercicio de renovación. Si el acento se pone en la regeneración natural, si el enriquecimiento en especies de interés colonial lo dirige la capacidad de dispersión de cada individuo, se trata de evitar aquellas actividades que puedan impedirla. La regulación de carácter cultural recae sobre el indígena y su agricultura nómada de roza y plantación. Para la empresa forestal, el acento se pone en la regulación de carácter fiscal, a pesar de las obligaciones de repoblación que asume y de la preocupación que en determinados momentos se manifiesta por su escaso cumplimiento.

La práctica forestal que se despliega en la colonia hace difícil defender que los primeros estudios que se elaboran a finales de la década de 1920 suponen el punto de partida de un discurso técnico constante en el tiempo que dirige el aprovechamiento de la selva. La aplicación en la Guinea continental de métodos científicos de ecología forestal con el objeto de producir la mayor cantidad de madera en un contexto extravertido sólo se atisba levemente en la colonia. Con independencia de este hecho, lo relevante es señalar que el discurso y los conocimientos forestales que se trasladan desde la metrópoli se alinean sin ningún tipo de matices con la práctica colonial, con el horizonte que ésta dibuja, con las exigencias que impone y con el extractivismo que alimenta. Es más, el grueso se elabora durante el primer franquismo. Un momento en el que las necesidades de posguerra y el ensueño autárquico parecen dibujar un horizonte relevante para la contribución de las maderas coloniales en la economía española. 


\section{Bibliografía}

AGGOR S.A. Maderas tropicales. Folleto documental editado bajo los auspicios del Comité National des Bois Tropicaux (París). Bilbao: Elèxpuru Hermanos, 1952, 36 p.

AUBRÉVILLE, André. Comment constituer une forêt tropicale de rapport. Revue de botanique appliquée et d'agriculture coloniale, 1929, nº 97, p. 560-568.

BERGERET, Anne. Discours et politiques forestières coloniales en Afrique et à Madagascar. Revue française d'histoire d'Outre-Mer, 1993, Tomo 80 (298), p. 23-47

BLAIS, Hélène; DEPREST, Florence y SINGARAVÉLOU, Pierre. Introduction. Pour une histoire spatiale du fait colonial. In BLAIS, Hélène.; DEPREST, Florence. y SINGARAVÉLOU, Pierre -Dir.- Territoires impériaux. Une histoire spatiale du fait colonial. París: Publicaciones de la Sorbonne, 2011, p. 7-21.

BRYANT, Raymond. L. Romancing Colonial Forestry: The Discourse of "Forestry as Progress" in British Burma. The Geographical Journal, 1996, vol. 162(2), p. 169-178.

BUCHY, Marlène. Histoire forestière de l'Indochine (1850-1954). Perspectives de recherché. Revue française d'Histoire d'Outre-Mer, 1993, Tomo 80 (229), p. 210-249.

CAPDEVIELLE, Juan Manuel. El bosque de la Guinea. Exploración y explotación. Madrid: Dossat, 1947.

CAPDEVIELLE, Juan Manuel. Tres estudios y un ensayo sobre temas forestales de la Guinea continental española. Madrid: Instituto de Estudios Africanos, 1949.

CARNERO, Fernando y DÍAZ, Álvaro. Aproximación a la economía de Guinea Ecuatorial durante el período colonial. Revista de Historia Contemporánea, 2014, $\mathrm{n}^{\circ}$ 49, p. 707-734.

CASALS, Vicente. Los ingenieros de montes en la España contemporánea (1848-1936). Barcelona: Ediciones del Serbal, 1996.

CASTRO, Mariano Luis y CALLE, María Luisa. La colonización española en Guinea Ecuatorial (1858-1900). Barcelona: Ceiba Ediciones, 2007.

CATINOT, Robert. Les éclaircies dans les peuplements artificiels de forêt dense africaine. Principes de base et application aux peuplements artificiels d'okoume. Bois et Forêts des Tropiques, 1969, $\mathrm{n}^{\circ} 126$.

CLEARY, Mark. Managing the forest in colonial Indochina. C. 1900 -1940. Modern Asian Studies, 2005, vol. 39(2), p. 257-283.

DARGAVEL, John y JOHANN, Elizabeth. Science and hope. A forest history. Cambridge: The White Horse Press, 2013.

DIRECCIÓN GENERAL DE MARRUECOS Y COLONIAS. Territorios Españoles del Golfo de Guinea. Resúmenes de los años 1946 y 1947. Madrid: 1949.

DIRECCIÓN GENERAL DE MARRUECOS Y COLONIAS. Resúmenes estadísticos del África Española. Madrid: Instituto de Estudios Africanos, 1954.

FOXÁ, Jaime. La palmera de aceite en la Guinea continental española. Revista Montes, 1945, nº 1, p. 5-8.

FUSTER, Pedro. Estudio sobre la constitución y explotación del bosque de la Guinea continental española. Madrid; Diana Artes Gráficas, 1941. 
FUSTER, Pedro y GONZÁLEZ MARTÍN, Luciana. Primera contribución al conocimiento de las maderas de la Guinea Continental Española. Madrid: Ediciones del Instituto de Estudios Africanos y de la Dirección General de Marruecos y Colonias, 1947.

GARCÍA ESTEBAN, Luis. y MARTÍNEZ, Pedro. Ayer y hoy de Guinea Ecuatorial. Bois et Forêts des Tropiques, 2000, vol. 266(4), p. 71-78.

GARCÍA PEREDA, Ignacio. Ingenieros de montes españoles en Guinea Ecuatorial (1928-1968). Colóquio Internacional Conhecimento e Ciência Colonial. Lisboa, 2013

GARCÍA PEREDA, Ignacio. La aeronáutica española y los ingenieros de montes en el primer tercio del siglo XX. In GONZÁLEZ, Francisco -Coord.- Ciencia y técnica entre la Paz y la Guerra. 1714, 1814, 1914. Madrid: Edt. SEHCYT, 2015, p. 333-340.

GARRIDO, Antonio. Los inicios de la gestión forestal española en el Norte de Marruecos: 1917-1927. Jaén: Universidad de Jaén, 2014.

GIORGI, Chiara. L'Africa come carriera. Funzioni e funzionari del colonialismo italiano. Roma: Carocci editore, 2012.

GÓMEZ, Josefina. Ciencia y politica de los montes españoles (1848-1936). Madrid: ICONA, 1992.

GÓMEZ, Josefina y MATA, Rafael. Acciones forestales públicas desde 1940: objetivos, criterios y resultados. Revista Agricultura y Sociedad, 1992, nº 65, p. 15-64.

GONZÁLEZ ALDAMA, Antonio. Estudio de la regeneración de las masas forestales en la Guinea Española. Madrid: Proyecto Fin de Carrera. ETSI de Montes. 1950.

GONZÁLEZ MARTÍN, Luciana. Primera contribución al conocimiento de las maderas de la Guinea Continental Española, Fasc. 2. Madrid: Ediciones del Instituto de Estudios Africanos, 1953.

GUERRA, Juan Carlos y PASCUAL, Henar. The Most Magnificent Spectacle in the Colony. Forestry Capitalism and Space Production in the Former Spanish Continental Guinea". 16th Conference of Historical Geographers. Londres: Royal Geographical Society, 2015a, https://www.researchgate.net/publication/279204455_The_most_magnificent_spectacle_in_the_Colony_forestry_capitalism_and_space_production_in_ the_former_Spanish_continental_Guinea [consulta: 15 de marzo de 2018].

GUERRA, Juan Carlos y PASCUAL, Henar. Dominando la colonia: Cartografía forestal, negocio de la madera y apropiación del espacio en la antigua Guinea Continental española. Scripta Nova: Revista electrónica de geografía y ciencias sociales, [En línea], 2015b, Vol XIX (525) http://www.ub.edu/geocrit/sn/sn-525.pdf [consulta: 15 de marzo de 2018].

GUERRA, Juan Carlos y PASCUAL, Henar. La selva como argumento: imaginario geográfico, discurso forestal y espacio colonial en Guinea Ecuatorial (1901-1968). Cuadernos Geográficos, 2017, Vol. 56 (1), p. 6-25. http://revistaseug.ugr.es/index.php/ cuadgeo/article/view/4702 [consulta: 15 de marzo de 2018]

GUILLARD, Joanny. Au service des forêts tropicales. Histoire des services forestiers français d'outre-mer. 1896-1960. Nancy: AgroParistech, 2014 [consulta: 18 de julio de 2018] 
LANZ, Tobias. J. The Origins, Development and Legacy of Scientific Forestry in Cameroon. Environment and History, 2000, nº 6, p. 99-120.

LASSERRE, Guy. Okoumé et chantiers forestiers du Gabon. Cahiers d'outre-mer, 1955, no 30, p. 119-160.

LUENGO, Emilio. Juan Capdevielle San Martín. Memorias de un forestal en Guinea entre 1928 y 1963. Revista Montes, 2017, n 130, p. 68-71.

MCELWEE, Pamela D. Forest Are Gold. Trees, People, and, Environmental Rule in Vietnam. Seattle: University of Washington Press, 2016.

MUNSHI, Indra. Colonialism and professionalism: a German forester in India. Environment and History, 1996, n 2, p. 195-219.

NÁJERA, Fernando. La Guinea española y su riqueza forestal: conferencia dada en el Instituto de Ingenieros Civiles el día 14 de diciembre de 1929. Madrid: Instituto Forestal de Investigaciones y Experiencias, 1930.

NÁJERA, Fernando. El abastecimiento del mercado nacional de maderas: conferencia pronunciada el día 5 de mayo de 1948 en el Instituto de Estudios Africanos. Archivo de Estudios Africanos, 1948, no 5.

NÁJERA, Fernando. Abastecimiento nacional de traviesas: estudio de las maderas tropicales españolas aptas para esta aplicación. Madrid: Blass, s.a., 1950.

NÁJERA, Fernando. El bosque y las maderas tropicales africanas en la economía nacional: conferencia dada en el Instituto de Ingenieros Civiles el dia 14 de diciembre de 1929. Madrid: Diana Artes Gráficas, 1957.

IFIE. Laboratorio de la Madera. Relación nominal de las especies maderables de la Guinea Española. Madrid, 1929.

ORTEGA, Modesto. Consideraciones sobre la palmera de aceite. Revista Montes, 1954, no 57, p. 191-194.

ORTEGA, Modesto. Algo más sobre la palmera de aceite. Revista Montes,1955, nº 63, p. 209-292.

PASCUAL, Henar y GUERRA, Juan Carlos. Civilizando la selva: capital, espacio y negocio forestal en la antigua Guinea continental española, c. 1926-1936. Revista Historia Agraria, 2017, nº 72, p. 135-166.

PEMÁN, Jesús; IRIARTE, Iñaki y LARIO, Francisco José. La restauración forestal de España: 75 años de una ilusión. Madrid: Ministerio de Agricultura y Pesca, Alimentación y Medio Ambiente, 2017.

PUYO, Jean-Yves. De la théorie a la pratique: les forestiers françaises face au défi colonial (1880-1940) In BOURDELAY, Vincent y SOUBEYRAN, Olivier. -Edts.- Milieu, colonisation et développement durable. Perspectives géographiques sur l'aménagement. París: L'Harmattan, 2000, p. 155-174.

RIBOT, Jesse. Historique de la gestion forestière en Afrique de l'Ouest. Ou: comment la "science" exclut les paysans. IIED. 2001, Drylands Issue Paper [consulta: 29 de marzo de 2018]

ROMERO, Ángel. Proyecto de explotación de una concesión forestal situada en la cuenca del río Tega. Superficie 22.000 Has. Madrid: ETSI de Montes. UPM, 1963, Proyecto Fin de Carrera. 
ROYO, Francisco. Explotación de 30.000 Has en Guinea Ecuatorial. Madrid: ETSI de Montes. UPM, 1969, Proyecto Fin de Carrera.

SANZ, Jesús. La historia contemporánea de los montes públicos españoles, 1812-1930. Notas y reflexiones (II). In GARRABOU, Ramón; BARCIELA, Carlos y JIMÉNEZ-BLANCO, José Ignacio. -Edts.- Historia agraria de la España contemporánea. 3. El fin de la agricultura tradicional (1900-1960). BARCELONA: Editorial Crítica, 1986, p. 142-170.

TANO, Kassi Pascal. Les bois dans l'économie de la Côte d'Ivoire. Paris: L'Harmattan, 2016

VANDERGEST, Peter y LEE, Nancy. Empire of Forestry: professional forestry and State Power in Southeast Asia. Part. 1. Environment and History, 2006 Vol. 12(1), p. 31-64.

WEIL, Ben. Conservation, exploitation and cultural change in the Indian Forest Service, 1875-1927. Environment and History, vol. 11(2), 2006, p. 319-343.

YUFANYI, Mbolo. The colonial heritage and post-colonialinfluence, entanglements and implications of the concept of community forestry by the example of Cameroon. Forest Policy and Economics, 2002, no 15, p. 70-77.

ZAPATA, Santiago. La madera en España (c. 1850 - c.1950): un primer esbozo. Revista de Historia Económica, 2001, nº 19 (2), p. 287-343.

(c) Copyright: Juan Carlos Guerra Velasco, 2019

(c) Copyright: Scripta Nova, 2019

GUERRA VELASCO, Juan Carlos; Ciencia forestal, práctica técnica, politica de la madera y contexto colonial en Guinea Ecuatorial (1929-1968), Barcelona: Universitat de Barcelona, 1 de mayo de 2019, vol. XXIII, $\mathrm{n}^{\circ}$ 613. [ISSN: 1138-97] 